\title{
Impact of COVID-19 Pandemic on the Psychological Outcomes: Multiple Indicators and Multiple Causes (MIMIC) Modeling
}

Musheer A. Aljaberi

Taiz University

Naser A. Alareqe

Taiz University

Mousa A. Qasem

University of Malaya

Abdulsamad Alsalahi

Sana'a University

\section{Sarah Noman}

Universiti Putra Malaysia

Md. Uzir Hossain Uzir

Universiti Putra Malaysia

Lubna Ali Mohammed

Lincoln University College (LUC)

Rukman Awang Hamat ( $\square$ rukman@upm.edu.my )

Universiti Putra Malaysia

\section{Research Article}

Keywords: COVID-19, psychological impact, post-traumatic stress disorder, Depression, Anxiety, Insomnia

Posted Date: September 27th, 2021

DOl: https://doi.org/10.21203/rs.3.rs-854593/v1

License: (c) (1) This work is licensed under a Creative Commons Attribution 4.0 International License.

Read Full License 


\section{Abstract}

Background: Due to the limited research examining the psychological impact of coronavirus disease 2019 (COVID-19), our study aims to investigate the effect of the COVID-19 pandemic on psychological outcomes and assess the differences between participants with and without post-traumatic stress disorder (PTSD) on the psychological outcomes as latent factors and items.

Methods: An online survey was conducted on 999 participants. The Impact of Event Scale-Revised (IES-R) assessed the psychological impact, while outcomes were measured by Patient Health Questionnaire-9 (PHQ-9), Generalized Anxiety Disorder (GAD-7), and Insomnia Severity Index (ISI). A series of Confirmatory Factor Analysis (CFA), structural equation model (SEM), Multiple Indicators and Multiple Causes (MIMIC), and Differential Item Functioning (DIF) were conducted.

Results: The IES-R has significant effects on the psychological outcomes. Participants with PTSD have a higher impact on latent factors (depression, anxiety, and insomnia) than those without PTSD. Among participants, $36.5 \%$ experienced moderate to severe symptoms of depression, and $32.6 \%$ had mild depressive symptoms. For anxiety, $23.7 \%$ of respondents experienced moderate to severe anxiety symptoms, and $33.1 \%$ had mild symptoms of anxiety. For the ISI, $51.5 \%$ of participants experienced symptoms of insomnia. Conclusion: the IES-R for COVID-19 has a significant impact on depression, anxiety, and insomnia at the level of latent constructs and observed variables.

\section{Introduction}

The coronavirus disease 2019 (COVID-19) pandemic has become an extreme health emergency [1] because the number of infected people exceeds 183 million, with 4 million deaths worldwide up to July 6 , 2021 [2]. Moreover, the COVID-19 has wreaked havoc on the world's healthcare infrastructure, daily wellbeing and routine, business, transportation, lifestyle, freedom of movement, schools, distribution of medical properties, and economy [3-9]. For such reasons, it is critical to understand how the population has dealt with this significant crisis [10]. Recalling the memory of the severe acute respiratory syndrome (SARS) pandemic, moderate-to-severe post-traumatic stress symptoms were recorded in the afflicted areas [11]. Similarly, the impact of Middle East Respiratory Syndrome (MERS), H1N1 influenza (swine flu), and Ebola pandemics on psychological health such as depression and substance abuse have been documented [12].

The COVID-19 pandemic provoked psychological distress among the general population [13-15]. It has been reported that $71 \%$ out of 4615 participants experienced psychological distress [16]. A study on healthcare workers reported that frontline health care professionals' anxiety, depression, and secondary traumatization scores on the COVID-19 were considerably higher than those of other health professionals or non-medical professionals [17]. Moreover, healthcare practitioners, who were afraid of being infected with COVID-19, felt stigmatized and experienced significant levels of anxiety, depressive symptoms, and sleep disorders. In addition, poor sleep quality was linked to high anxiety and depression symptoms in the 
general population and health care workers [18-20]. In line with this, others have reported that the frequency of stress, anxiety, and distress was high among academicians. At the same time, out of 349 physicians, $47.9 \%$ experienced anxiety symptoms, $60.2 \%$ were distress, $21.8 \%$ had burnout, and $10.6 \%$ were screened positive for depression symptoms [21].

On the other hand, the COVID-19 exacerbated the psychological symptoms in persons with a mental health problem $[22,23]$. For example, psychiatric patients scored considerably higher on the overall IES-R, DASS-21 depression, anxiety, and stress subscales during the peak of the COVID-19 pandemic with stringent lockout measures. PTSD-like symptoms and moderate to severe insomnia were reported to be more than $25 \%$ of psychiatric patients. They had considerably more moderate to severe clinical insomnia than healthy controls [6]. In addition, the experience of being isolated may be harmful since the data revealed that a significant number of people suffered from a variety of long-term mental health issues $[12,22]$.

A few articles have been published about the COVID-19's psychological impact on the general population [6, 24-28]. Furthermore, previous studies have indicated a broad spectrum of psychological effects on people during the COVID-19 pandemic at the individual, community, and worldwide levels $[15,24]$. Therefore, there is an imperative need to have high-quality data examining the psychological impacts of the COVID-19 pandemic across the general population [29]. Although the conducted studies focused on measuring the effects of the COVID-19 pandemic on psychological health, there is a lack of investigation on validating and utilizing the measurement scales and instruments to measure the impact and psychological outcomes of COVID-19 worldwide. Hence, the current study aims to carry out an advanced psychometric analysis on the impact of the COVID-19 pandemic using IES-R on psychological outcomes using Patient Health Questionnaire-9, Generalized Anxiety Disorder (GAD-7), and Insomnia Severity Index (ISI) to measure the depression, anxiety, and insomnia respectively, and to assess the differences between participants with and without PTSD on such psychological effects as latent factors and items within Multiple Causes and Multiple Indicators (MCMI) and Differential Item Functioning (DIF) framework.

\section{Materials And Methods}

\subsection{Design and sample of the study}

A cross-sectional survey design using an anonymous online questionnaire was adopted to measure the psychological response during the COVID-19 pandemic. This study fulfilled the criteria of a descriptive and correlational casualty design based on an analysis of covariance matrix. The online survey was used to reduce the face-to-face interactions with all participants. Google Forms were used to generate an online survey that was sent later via a hyperlink.

\subsection{Participants}


A total of 999 individuals from different countries (20 countries) participated in this study. Before the data collection procedures, all participants were briefed via a Google Form about the purpose of the study, data privacy, and its exclusive scientific use, and submitted their informed consent. A convenience sampling approach was used to recruit participants. The usage of social media was the recruitment method. The participants' confidentiality was protected throughout the data collection and analysis to guarantee data integrity. Participants were requested to engage in the study willingly.

\subsection{Instruments}

The survey was divided into two sections: socio-demographic data and COVID-19-related data explicitly created for this study using a validated and reliable questionnaire including the Impact of Event ScaleRevised (IES-R), Patient Health Questionnaire-9 (PHQ-9), the 7-item Generalized Anxiety Disorder (GAD-7), and Insomnia Severity Index (ISI), which were used as data collection tools.

The Impact of Event Scale-Revised (IES-R) was used to assess COVID-19's psychological impact. The IES$\mathrm{R}$ is a self-administered questionnaire that has been well-validated in different regions worldwide to measure the level of psychological impact within two weeks of exposure to a public health crisis. The scale consists of 22 items categorized into three subscales: avoidance, intrusion, and hyperarousal [30]. The overall IES-R mean score was classified into four categories; 0-23 (normal), 24-32 (mild psychological impact), 33-36 (moderate psychological impact), and $>37$ (severe psychological impact) [31]. Another categorization for IES-R was also performed for two groups; participants without Post Traumatic Stress Disorder (PTSD) scoring from 0 to 23 and with PTSD scoring more than 23.

The Patient Health Questionnaire-9 (PHQ-9) is a 9-item self-report instrument for screening, monitoring, diagnosis, and measuring the severity of depression [32]. The PHQ-9's psychometric qualities have already been established in Chinese populations [33]. According to recent studies by Civantos et al. and Kroenke et al. [21, 32], symptoms of depression were characterized as a total score of $\geq 5$ points on the PHQ-9. A cut-off of $\geq 10$ indicated a possible major depression, with a sensitivity of $80.0 \%$ and specificity of $92.0 \%$. The participants' response rate options were categorized as follows: $0=$ "not at all", $1=$ "several days", 2 = "more than half the days" and 3 = "nearly every day". The overall score varied from zero to 27 , with a higher score indicating more self-reported depression [34, 35]. The PHQ-9 total scores were grouped into four categories: 0-4 (normal), 5-9 (mild depressive disorder), 10-14 (moderate depressive disorder), 15-19 (moderately severe depressive disorder), and 20-27 (severe depressive disorder) [36].

The 7-item Generalized Anxiety Disorder (GAD-7) Scale was used to evaluate anxiety symptoms during the previous two weeks. The GAD-7 has already been utilized and confirmed to be a reliable tool for assessing anxiety symptoms $[18,21,37]$. The GAD-7 Scale scores ranged from $0-21$, and a score of 10 was reported to be the endpoint for detecting cases of GAD-7 $\geq 10$ (high anxiety). The scores were grouped into four categories: normal (0-4), mild (5-9), moderate (10-14), and severe (15-21) [18, 21].

Finally, insomnia was assessed via the Insomnia Severity Index (ISI) [38]. The 7-item self-report index ranged from 0-28 and was used to determine the severity of insomnia by the scoring system as follows: 
no significant insomnia (0-7), subthreshold insomnia (8-14), moderately severe insomnia (15-21), and severe insomnia $(22-28)[6,39,40]$.

\subsection{Data processing and analysis \\ 2.4.1. Model Fit of Structural Equation Modeling (SEM)}

Generally, model fit of Confirmatory Factor Analysis (CFA), measurement model, Structural Equation Model (SEM), Multiple Indicators and Multiple Causes (MIMIC), and Differential Item Functioning (DIF) are determined by using several approximate fit indices, such as the Comparative Fit Index (CFI), Incremental Fit Index (IFI), Tucker Lewis Index (TLI), Standardized Root Mean Residual (SRMR), and the Root Mean Squared Error of Approximation (RMSEA) with a confidence interval of lower and upper limits.

The model-data fit was determined according to RMSEA and CFI values. Good model-data fit was based on the RMSEA and CFT values of 0.06 or less and 0.95 or above, respectively [41]. The acceptable modeldata fit was determined by RMSEA values of 0.08 and CFI values of 0.90 [42], while the perfect modeldata fit was determined by RMSEA values of 0.000 and CFI values of 1.000. SRMR, IFI, and TLI values were conducted with a similar rate to RMSEA and CFI. Statistical significance was tested based on a critical ratio (C.R) above 1.964 and a $p$-value of less than $0.05[43,44]$. Factor loading was preferred to be at 0.60 , and if the value was less than 0.60 , it was subjected to removal.

\subsubsection{Multiple Indicators and Multiple Causes (MIMIC)}

KG Joreskog and AS Goldberger [45] described the Multiple Indicators and Multiple Causes model as a particular application of structural equation modeling (SEM). The MIMIC model is essential in validating the research because it enables multi-group variations on a latent construct to be investigated [46]. According to the membership group interpretation method, a significant positive regression coefficient suggests a more excellent value for one group's specific component. In contrast, a significant negative regression coefficient implies a lower value on the particular factor for another group. The measurement set could detect possible DIF in the observed indicators of latent variables [47].

\subsubsection{Multiple Indicators-Multiple Causes (MIMIC) for Differential Item Functioning (DIF)}

DIF is a statistical character used to determine if an assessment has a systematic bias due to constructirrelevant variables. DIF depicts the degree of performance on a given item is systematically varied. For example, the DIF is proved when examinees in subgroups (e.g., race/ethnicity, gender, socioeconomic status) with the same level of latent qualities have differing probabilities of responding correctly to a particular item [48].

MIMIC confirmatory factor analysis is used to examine DIF in polytomous items, which are commonly used in educational assessments (e.g., constructed-response items) and psychological inventories (e.g., Likert-type items and rating scale items) [49]. One latent factor is regressed on an observable grouping 
variable in a simple MIMIC model to allow group means differences on the factor. An item is assessed for DIF by regressing it (i.e., replies to it) on the grouping variable. If a group association strongly predicts item replies after adjusting for group mean differences on the factor, there is evidence of different functioning [50]. For this research, the MIMIC method with a pure anchor (denoted as M-PA) was conducted. M-PA means where all items are studied except Item 1, which is the anchored item [49]. When an item on a test has distinct measuring qualities for one group of persons versus another, regardless of group-mean differences on the variable under investigation, this is known as DIF. DIF detection is critical due to the fact that it can lead to erroneous assumptions or decisions about group variances and invalidate techniques for determining conclusions about an individual.

\section{Results}

\subsection{Demographic Variables}

A total of 999 participants were recruited from 20 countries around the world. The majority of participants were from Malaysia, Yemen, Indonesia, Nigeria, and Sri Lanka, followed by other countries (Fig. 1). In the present study, $64 \%$ of the participants $(n=639)$ were without PTSD, while $36.0 \%(n=360)$ were experiencing PTSD. Females $(n=554 ; 55.5 \%)$ slightly predominated the overall sample versus males $(n=$ $445 ; 45.5 \%$ ). Based on the 22-item IES-R scoring, $35.6 \%$ of the females experienced PTSD versus $36.6 \%$ of males. In terms of marital status, $46.4 \%$ of participants were single, while $49.6 \%$ were married. The majority of the participants $(n=551 ; 55.2 \%)$ were students, followed by participants who work in an educational profession ( $n=230 ; 23 \%)$. In terms of education level, $(n=604 ; 60.5 \%)$ of the participants had a postgraduate qualification (master's or Ph.D. degrees) (Table 1). 
Table 1

Socio-demographic characteristics of participants

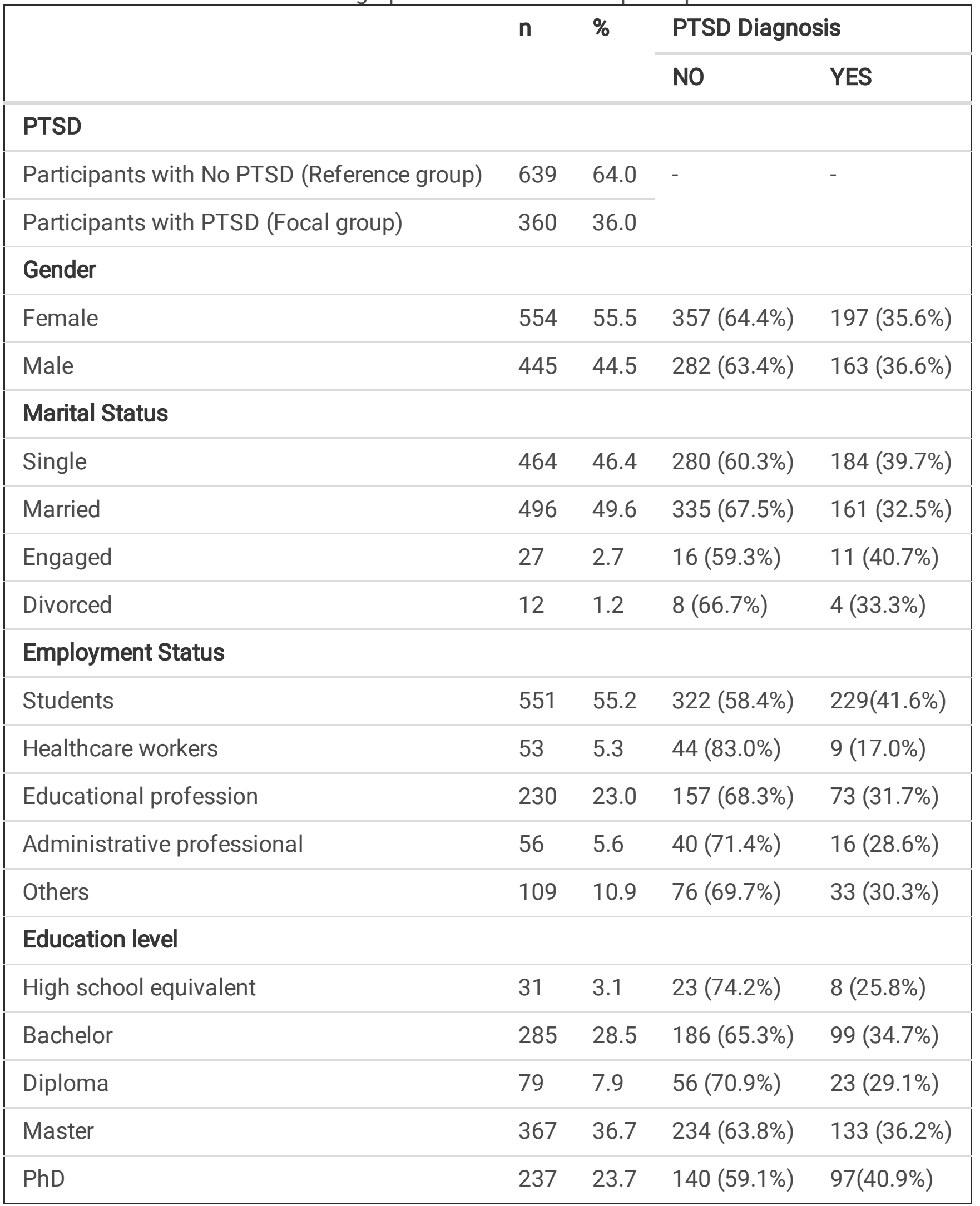

The study characteristics of the psychological impact of COVID-19, along with associated psychological disorders including depression, anxiety, and insomnia, are summarized in Table 2. The psychological impact of COVID-19 was assessed using the IES-R, and the overall mean score was $1.748( \pm 1.145)$. The majority of the participants $(n=639 ; 64.0 \%)$ experienced a normal psychological impact while $(n=146$; 
$14.6 \%)$ had a mild psychological impact. This is followed by participants who had moderate psychological impact $(n=41 ; 4.1 \%)$, and severe psychological impact $(n=173 ; 17.3 \%)$. In terms of depression, the mean score was $2.325( \pm 1.24)$, and 308 participants $(30.8 \%)$ had no symptoms, while $326(32.6 \%)$ and $179(17.9 \%)$ of them had mild and moderate depressive symptoms, respectively.

Additionally, 104 (10.4\%) participants experienced moderately severe depression, while 82 (8.2\%) had severe depression. Regarding anxiety, the mean score was 1.897 ( \pm 0.96719$)$, and 43 (43.1\%) participants had no anxiety, while other participants experienced mild anxiety $(n=331 ; 33.1 \%)$, moderate $(n=145$; $14.5 \%)$ and severe anxiety $(n=92 ; 9.2 \%)$. Regarding insomnia, the mean score was $1.759( \pm 0.868)$ and four categories of insomnia were identified among the participants including those with no clinically significant insomnia $(n=484 ; 48.4 \%)$, sub-threshold insomnia $(n=312 ; 31.2 \%)$, moderate severity clinical insomnia $(n=162 ; 16.2 \%)$, and severe clinical insomnia $(n=41 ; 4.1 \%)$. 
Table 2

Levels of the psychological impact of COVID-19, depression, anxiety, and insomnia among 999 participants in this study.

\begin{tabular}{|c|c|c|}
\hline Levels & Frequency (n) & Percent (\%) \\
\hline \multicolumn{3}{|l|}{ IES-R Levels } \\
\hline $0-23$ (normal) & 639 & 64.0 \\
\hline 24-32 (mild psychological impact) & 146 & 14.6 \\
\hline 33-36 (moderate psychological impact) & 41 & 4.1 \\
\hline > 37 (severe psychological impact) & 173 & 17.3 \\
\hline \multicolumn{3}{|l|}{ Depression Levels } \\
\hline$(0-4)$ No Symptoms & 308 & 30.8 \\
\hline (5-9) Mild Depressive Symptoms & 326 & 32.6 \\
\hline (10-14) Moderate Depressive Symptoms & 179 & 17.9 \\
\hline (15-19) Moderately Severe Depression & 104 & 10.4 \\
\hline$(<20)$ Severe Depression & 82 & 8.2 \\
\hline \multicolumn{3}{|l|}{ Anxiety Levels } \\
\hline$(0-4)$ normal & 431 & 43.1 \\
\hline$(5-9)$ mild & 331 & 33.1 \\
\hline (10-14) moderate & 145 & 14.5 \\
\hline$(15-21)$ severe & 92 & 9.2 \\
\hline \multicolumn{3}{|l|}{ Insomnia Levels } \\
\hline $0-7=$ No clinically significant insomnia & 484 & 48.4 \\
\hline $8-14=$ Sub threshold insomnia & 312 & 31.2 \\
\hline 15-21 = Clinical insomnia (moderate severity) & 162 & 16.2 \\
\hline 22-28 = Clinical insomnia (severe) & 41 & 4.1 \\
\hline
\end{tabular}

\subsection{Descriptive Statistics}

\subsubsection{Impact of Event Scale-Revised (IES-R) for COVID - 19}

As shown in Appendix A, the overall means score of intrusion, avoidance, and hyperarousal dimensions of the IES-R scale were $0.90,1.07$, and 0.91 with a standard deviation of $\pm 1.045, \pm 1.15$, and \pm 1.12 , 
respectively. All variables were normally distributed within the acceptable standard since the skewness and kurtosis were \pm 3 and \pm 7 , respectively. The overall reliabilities for each dimension of the IES-R scale and each item were above average, with 0.70 to reach 0.88 as a slightly excellent degree. Appendix D presents items and symbols of IES-R for Covid-19.

\subsubsection{Psychological Outcomes}

The overall means of depression, anxiety, and insomnia were $0.86,0.907$, and 1.27 , with a standard deviation of $\pm 0.94, \pm 0.932$, and \pm 1.13 , respectively. The skewness $( \pm 3)$ and kurtosis $( \pm 7)$ of these variables indicated the values were acceptable within the acceptable standards. Furthermore, the overall reliabilities for each factor and each item were above the average rate of 0.70 to reach 0.90 as an excellent degree (Appendix B).

\subsection{Measurement models}

\subsubsection{Model 1: Impact of Event Scale-Revised (IES-R) for COVID-19}

In the first order for the original model of Impact of Event Scale-Revised for COVID-19 with three dimensions: intrusion with 8 items, avoidance with 8 items, and hyper arousal with 6 items could not reach for the satisfactory fit indices $(\mathrm{CFI}(\geq 0.90)=0.853$,IFI $(\geq 0.90)=0.0854, \mathrm{TLI}(\geq 0.90)=0.835$, SRMR $(\leq 0.08)=0.057$, RMSEA $(\leq 0.08)=0.092, \mathrm{Cl} / \mathrm{HI}(<0.08)=0.088$, and $\mathrm{Cl} / \mathrm{LO}(<0.08)=0.096)($ Fig. 2 and Table 3). 
Table 3

Model Fit for IES-R for Covid-19 and Psychological Outcome

\begin{tabular}{|c|c|c|c|c|c|c|c|}
\hline Models & $\begin{array}{l}\text { CFI } \\
(\geq .90)\end{array}$ & $\begin{array}{l}\text { IFI } \\
(\geq .90)\end{array}$ & $\begin{array}{l}\text { TLI } \\
(\geq .90)\end{array}$ & $\begin{array}{l}\text { SRMR } \\
(\leq .08)\end{array}$ & $\begin{array}{l}\text { RMSEA } \\
(\leq .08)\end{array}$ & $\begin{array}{l}\mathrm{Cl} / \mathrm{HI} \\
(<.08)\end{array}$ & $\begin{array}{l}\mathrm{Cl} / \mathrm{LO} \\
(<.08)\end{array}$ \\
\hline IES-R for Covid-19 & 0.853 & 0.854 & 0.835 & 0.057 & 0.092 & 0.088 & 0.096 \\
\hline Figure 2 & 0.935 & 0.935 & 0.923 & 0.067 & 0.070 & 0.065 & 0.075 \\
\hline $\begin{array}{l}\text { Psychological } \\
\text { Outcomes }\end{array}$ & 0.911 & 0.911 & 0.901 & 0.047 & 0.069 & 0.066 & 0.073 \\
\hline Figure 3 & 0.929 & 0.929 & 0.920 & 0.0482 & 0.067 & 0.071 & 0.063 \\
\hline $\begin{array}{l}\text { Structural } \\
\text { Regression }\end{array}$ & 0.985 & 0.985 & 0.972 & 0.026 & 0.082 & 0.064 & 0.102 \\
\hline Figure 4 & 0.995 & 0.995 & 0.989 & 0.0153 & 0.051 & 0.030 & 0.073 \\
\hline $\begin{array}{l}\text { Structural } \\
\text { Regression } \\
\text { Figure } 5\end{array}$ & 1.000 & 1.000 & 1.004 & 0.0005 & 0.000 & 0.032 & 0.000 \\
\hline $\begin{array}{l}\text { MIMIC } \\
\text { Fig.6/7 }\end{array}$ & 0.929 & 0.920 & 0.929 & 0.046 & 0.065 & 0.061 & 0.068 \\
\hline $\begin{array}{l}\text { MIMIC for DIF } \\
\text { Figure } 8 / 9\end{array}$ & 0.932 & 0.932 & 0.916 & 0.044 & 0.066 & 0.062 & 0.070 \\
\hline $\begin{array}{l}\mathrm{CFI}=\text { comparative } \\
\text { root mean residual, } \\
\text { High limit, } \mathrm{Cl} / \mathrm{LO}= \\
\text { DIF = Differential It }\end{array}$ & $\begin{array}{l}\text { ndex, IF } \\
\text { MSEA = } \\
\text { fidence } \\
\text { Functic }\end{array}$ & $\begin{array}{l}\text { ncreme } \\
\text { t mean } \\
\text { terval of } \\
\text { ig. }\end{array}$ & $\begin{array}{l}\text { I fit in } \\
\text { uared } \\
\text { w lim }\end{array}$ & $\begin{array}{l}\mathrm{LI}=\mathrm{T} \\
\mathrm{f} \text { app } \\
\mathrm{MI}=1\end{array}$ & $\begin{array}{l}\text { Lewis in } \\
\text { lation, } \mathrm{Cl} \\
\text { le Indica }\end{array}$ & $\begin{array}{l}\text { RMR = } \\
\text { Confide } \\
\text { id Mul }\end{array}$ & $\begin{array}{l}\text { dardized } \\
\text { Interval o } \\
\text { Causes, }\end{array}$ \\
\hline
\end{tabular}

Regarding the goodness of fit statistics for IES-R for COVID-19, six items were deleted, and the reason is that those items required error terms, resulting in non-positive variance. Therefore, the removal of the items was decided in keeping with the health error terms between items int1 and int3. As a result of this, the goodness of fit statistics was reasonable $(\mathrm{CFI}(\geq 0.90)=0.935$, IFI $(\geq 0.90)=0.935, \mathrm{TLI}(\geq 0.90)=$ $0.923, \operatorname{SRMR}(\leq 0.08)=0.067, \operatorname{RMSEA}(\leq 0.08)=0.070, \mathrm{Cl} / \mathrm{HI}(<0.08)=0.065$, and $\mathrm{Cl} / \mathrm{LO}(<0.08)=0.075)$. Three dimensions of IES-R for COVID-19: intrusion, avoidance, and hyperarousal, were statistically significant ( $T$-value $\geq 1.964$ and $p$-value $\leq 0.001$ ). The positive values of correlation ranged from 0.97 to 0.77, and the unstandardized estimation for all Impact of Event Scale-Revised items for COVID-19 was statistically significant ( $T$-value $\geq 1.964$ and $p$-value $\leq 0.001$ ). Moreover, the standardized estimation of Factor Loading was equal and above 0.60 as sufficient loading. The sufficient rate of average variance extracted (AVE) was above 0.50 , and excellent composite reliability coefficients were above 0.70 , reflecting the convergent validity of IES-R for COVID-19 (Fig. 2 and Appendix A). 


\subsubsection{Model 2: Psychological Outcome (Depression, Anxiety, and Insomnia)}

The hypothesized model's loading for one item of the depression factor (Item 9) was below 0.60. Therefore, this item was deleted to obtain high goodness of fit statistics. Subsequently, the goodness of fit statistics was reasonable $(\mathrm{CFI}(\geq 0.90)=0.929$, IFI $(\geq 0.90)=0.929, \mathrm{TLI}(\geq 0.90)=0.920, \mathrm{SRMR}(\leq$ $0.08)=0.048, \operatorname{RMSEA}(\leq 0.08)=0.067, \mathrm{Cl} / \mathrm{HI}(<0.08)=0.071$, and $\mathrm{Cl} / \mathrm{LO}(<0.08)=0.063)($ Fig. 3 and Table $3)$. The three factors of psychological outcomes: depression, anxiety, and insomnia, and the unstandardized estimation for all items were statistically significant ( $T$-value $\geq 1.964$ and $p$-value $\leq$ 0.001). The positive values of correlation ranged from 0.79 to 0.61 . Standardized estimation of Factor Loading was above 0.60 as sufficient loading (Fig. 3 and Appendix A). The sufficient rate of average variance extracted (AVE) was above 0.50 except for depression (0.48), and the excellent coefficients of composite reliability of above 0.70 were obtained, reflecting convergent validity of psychological outcomes.

\subsection{Objective 1: Effect of IES-R for Covid-19 on Psychological Outcomes}

\section{Model 2: IES-R for Covid-19 and Psychological Outcomes}

Table 4 illustrates mean, standard deviation, skewness, kurtosis, and correlation of hypothesized model of IES-R for COVID-19 and psychological outcomes. Error terms were correlated between anxiety and insomnia to reach excellent goodness of fit statistics. Subsequently, the goodness of fit statistics was reasonable $(\mathrm{CFI}(\geq 0.90)=0.995, \mathrm{IFI}(\geq 0.90)=0.995, \mathrm{TLI}(\geq 0.90)=0.989, \mathrm{SRMR}(\leq 0.08)=0.0153$, $\operatorname{RMSEA}(\leq 0.08)=0.051, \mathrm{Cl} / \mathrm{HI}(<0.08)=0.030$, and $\mathrm{Cl} / \mathrm{LO}(<0.08)=0.073)($ Fig. 4 and Table 3$)$. The results demonstrated a positive correlation between IES-R for COVID-19 (intrusion, avoidance, and hyperarousal) and psychological outcomes (depression, anxiety, and insomnia) and were statistically significant ( $T$-value $\geq 1.964$ and $p$-value $\leq 0.001, \mathrm{R}=0.71$ ) (Fig. 4 and Table 4 ). 
Table 4

Descriptive Statistics and Correlation Matrix for IES-R for Covid-19 and Psychological Outcomes (Depression, Anxiety, and Insomnia)

\begin{tabular}{|lllllllll|}
\hline & $\mathbf{1}$ & $\mathbf{2}$ & $\mathbf{3}$ & $\mathbf{4}$ & $\mathbf{5}$ & $\mathbf{6}$ & Skewness & Kurtosis \\
\hline Intrusion & 1.00 & & & & & & 1.029 & 0.794 \\
\hline Avoidance & 0.623 & 1.00 & & & & & 1.175 & 1.150 \\
\hline Hyperarousal & 0.779 & 0.705 & 1.00 & & & & 0.804 & 0.060 \\
\hline Depression & 0.513 & 0.451 & 0.568 & 1.00 & & & 0.736 & -0.122 \\
\hline Anxiety & 0.560 & 0.424 & 0.566 & 0.71 & 1.00 & & 0.868 & 0.276 \\
\hline Insomnia & 0.475 & 0.425 & 0.534 & 0.70 & 0.567 & 1.00 & 0.736 & -0.230 \\
\hline Mean & 5.07 & 3.35 & 7.36 & 8.07 & 8.63 & 8.93 & & \\
\hline Std. Deviation & 4.31 & 3.26 & 5.86 & 5.65 & 6.60 & 6.32 & & \\
\hline
\end{tabular}

The results indicated that the unstandardized estimation for all dimensions of IES-R for COVID-19 (intrusion, avoidance, and hyperarousal) and psychological outcomes (depression, anxiety, and insomnia) was statistically significant ( $T$-value $\geq 1.964$ and $p$-value $\leq 0.001)$. Furthermore, the standardized estimations of factor loading are excellent rate (above 0.70) (Fig. 4 and Table 5).

Table 5

Parameters of IES-R for Covid-19and Psychological outcomes

\begin{tabular}{|c|c|c|c|c|c|c|c|}
\hline Latent Variables & Factor & B & S.E & C.R & $\mathrm{p}$ & $\lambda$ & SMC \\
\hline IES-R for & Intrusion & 1.000 & - & - & - & 0.838 & 0.702 \\
\hline \multicolumn{8}{|l|}{ Covid-19 } \\
\hline & Avoidance & 1.219 & 0.045 & 27.110 & $\star \star \star$ & 0.750 & 0.563 \\
\hline & Hyper-arousal & 0.843 & 0.024 & 34.703 & $\star \star \star$ & 0.933 & 0.870 \\
\hline \multirow[t]{3}{*}{ Psychological Outcome } & Depression & 1.000 & - & - & - & 0.852 & 0.726 \\
\hline & Anxiety & 0.845 & 0.032 & 26.169 & $\star \star \star$ & 0.841 & 0.707 \\
\hline & Insomnia & 0.923 & 0.036 & 25.426 & $\star \star \star *$ & 0.821 & 0.675 \\
\hline \multirow[t]{2}{*}{ Correlation } & $\mathrm{F} 1-\mathrm{F} 2$ & 14.522 & 0.965 & 15.050 & $\star \star \star$ & 0.715 & 0.511 \\
\hline & e5-e6 & -4.421 & 0.729 & -6.064 & $\star * *$ & -0.400 & 0.160 \\
\hline $\begin{array}{l}\mathrm{B}=\text { unstandardized estim } \\
=\text { Squared Multiple Corre } \\
\text { significance at } 0.001\end{array}$ & $\begin{array}{l}\mathrm{s}, \mathrm{S} . \mathrm{E}=\text { Stande } \\
\mathrm{m}, \mathrm{F} 1=\mathrm{IES}-\mathrm{R} \mathrm{f}\end{array}$ & $\begin{array}{l}\text { or, C.R } \\
\text { ovid-19 }\end{array}$ & $\begin{array}{l}\text { ritical R } \\
D=\text { Psvo }\end{array}$ & $\begin{array}{l}\text { to, } P=p r \\
\text { ological }\end{array}$ & abili & $\begin{array}{l}\lambda=\text { loac } \\
\star \star \star\end{array}$ & g, SMC \\
\hline
\end{tabular}




\subsection{Structural Model}

\section{Model 2: Effect of IES-R for Covid-19on Psychological Outcome}

The results showed that the IES-R for COVID-19 (intrusion, avoidance, and hyperarousal) was positively associated with psychological outcomes (depression, anxiety, and insomnia) and this hypothesis was statistically significant $(b=1.114, \mathrm{SE}=0.054, T$-value $=20.556(\geq 1.964)$ and $p$-value $=0.001(\leq 0.001), \beta$

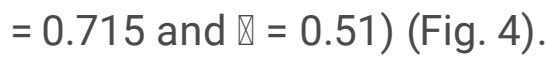

Figure 5 presents the hypothesized model of IES-R for COVID-19 as individual factors (intrusion, avoidance, and hyperarousal) and psychological outcomes as individual factors (depression, anxiety, and insomnia), which reached the perfect fit goodness statistics after correlating error terms of exogenous and endogenous factors. The goodness of fit statistics was highly reasonable (CFI $(\geq 0.90)=0.1000$, IFI $(\geq 0.90)=1.000, \mathrm{TLI}(\geq 0.90)=1.004, \operatorname{SRMR}(\leq 0.08)=0.001, \operatorname{RMSEA}(\leq 0.08)=0.000, \mathrm{Cl} / \mathrm{HI}(<0.08)=$ 0.032 , and $\mathrm{Cl} / \mathrm{LO}(<0.08)=0.000)$ (Fig. 5 and Table 3$)$. The results demonstrated that the intrusion, avoidance, and hyperarousal significantly and positively affected psychological outcomes; depression, anxiety, and insomnia. Hence, people who experienced the intrusion/ avoidance/ hyperarousal as the impact of COVID-19 would be subjected to experience depression, anxiety, and insomnia with the effect size of $0.34,0.36$, and 0.30 with the large effect size (above 0.25) [51] (see Fig. 5 and Table 6).

Table 6

Parameters of Impact of Covid-19 Based on IES-R on Individual Psychological outcomes

\begin{tabular}{|c|c|c|c|c|c|c|c|}
\hline $\begin{array}{l}\text { Individual psychological } \\
\text { outcomes }\end{array}$ & $\begin{array}{l}\text { IES-R for Covid- } \\
19\end{array}$ & B & S.E & C.R & $\mathbf{p}$ & $\lambda$ & 四 \\
\hline Depression & Intrusion & 0.255 & 0.063 & 4.014 & $\star \star \star$ & 0.166 & 0.34 \\
\hline Depression & Avoidance & 0.082 & 0.034 & 2.396 & 0.017 & 0.073 & \\
\hline Depression & Hyper arousal & 0.783 & 0.090 & 8.715 & $* * *$ & 0.387 & \\
\hline Anxiety & Intrusion & 0.398 & 0.053 & 7.487 & $\star \star \star$ & 0.303 & 0.36 \\
\hline Anxiety & Hyper arousal & 0.572 & 0.070 & 8.152 & $\star \star \star$ & 0.330 & \\
\hline Insomnia & Intrusion & 0.199 & 0.063 & 3.168 & 0.002 & 0.136 & 0.30 \\
\hline Insomnia & Avoidance & 0.081 & 0.038 & 2.125 & 0.034 & 0.075 & \\
\hline Insomnia & Hyper arousal & 0.728 & 0.090 & 8.043 & $\star \star \star$ & 0.376 & \\
\hline
\end{tabular}




\subsection{Objective 2: Groups with PTSD and without PTSD on psychological outcomes as Latent Constructs MIMIC Model}

The analysis of differences between participants with and without PTSD groups on the score of the threefactor model of psychological outcomes was conducted using the Multiple Indicators and Multiple Causes (MIMIC) model. Different codes represented group membership; 0 = participants without PTSD (a reference group), and 1 = participants with PTSD (a focal group). A path diagram of the MIMIC model of the three-factor model of psychological outcomes is given in Fig. 6. Correlated error terms among the three-factor model were conducted based on essential requirements of MIMIC model. Goodness of Fit indices in MIMIC model obtained plausible rate $(\mathrm{CFI}(\geq 0.90)=0.929, \mathrm{IFI}(\geq 0.90)=0.920, \mathrm{TLI}(\geq 0.90)=$ $0.929, \operatorname{SRMR}(\leq 0.08)=0.046, \operatorname{RMSEA}(\leq 0.08)=0.065, \mathrm{Cl} / \mathrm{HI}(<0.08)=0.061$, and $\mathrm{Cl} / \mathrm{LO}(<0.08)=0.068)$ (Fig. 6 and Table 3).

The regression of the latent three factors on group differences reflects the results in the mean structure case. Negative coefficients indicated that participants without PTSD scored lesser and had a negative effect on depression, anxiety, and insomnia compared to participants with PTSD, who scored higher with positive coefficients (Fig. 7 and Table 7). Table 7 shows the unstandardized and standardized solutions and the critical ratio for the three factors: depression, anxiety, and insomnia. The findings indicated that participants without PTSD were negatively scored and lesser than participants with PTSD on those mentioned factors.

\section{H1}

Participants without PTSD will score negatively less depression, while those with PTSD will score positively high depression. The results indicated that this hypothesis was statistically significant $(b=$ $-0.677, \mathrm{SE}=0.047, T$-value $=-14.435(\geq 1.964)$ and $p$-value $=0.001(\leq 0.001), \beta=0.518$ and $\otimes=0.27)$ for participants without PTSD (Fig. 6 and Table 7) and the same values for participants with PTSD, but in a positive direction pole (Fig. 7 and Table 7).

\section{$\mathrm{H} 2$}

Participants without PTSD will score negatively less anxiety, while participants with PTSD will score positively high anxiety. Results demonstrated that this hypothesis was statistically significant $(b=-0.750$, $\mathrm{SE}=0.049, T$-value $=-15.390(\geq 1.964)$ and $p$-value $=0.001(\leq 0.001), \beta=0.518$ and $\nabla=0.27)$ for participants without PTSD (Fig. 6 and Table 7) and the same values for participants with PTSD, but in a positive direction pole (Fig. 7 and Table 7). 
Participants without PTSD will score negatively less insomnia, while those with PTSD will score positively high. Results indicated that this research hypothesis was statistically significant $(b=-0.950, S E=0.059$,

$T$-value $=-16.144(\geq 1.964)$ and $p$-value $=0.001(\leq 0.001), \beta=0.509$ and $\nabla=0.26)$ for participants without PTSD (Fig. 6 and Table 7) and the same values for participants with PTSD, but in a positive direction pole (Fig. 7 and Table 7).

Table 7

Parameters of MIMIC Model

\begin{tabular}{|c|c|c|c|c|c|c|c|c|}
\hline & & & B & S.E & C.R & $P$ & Path & sing \\
\hline \multirow[t]{2}{*}{$\mathrm{H}_{1}$} & Depression & No PTSD & -0.677 & 0.047 & -14.435 & $\star \star \star *$ & 0.518 & 0.27 \\
\hline & & PTSD & 0.677 & 0.047 & 14.435 & $* * *$ & 0.518 & 0.27 \\
\hline \multirow[t]{2}{*}{$\mathrm{H}_{2}$} & Anxiety & No PTSD & -0.750 & 0.049 & -15.390 & $\star * *$ & 0.518 & 0.27 \\
\hline & & PTSD & 0.750 & 0.049 & 15.390 & $\star \star \star$ & 0.518 & 0.27 \\
\hline \multirow[t]{2}{*}{$\mathrm{H}_{3}$} & Insomnia & No PTSD & -0.950 & 0.059 & -16.144 & $\star \star \star *$ & 0.509 & 0.26 \\
\hline & & PTSD & 0.950 & 0.059 & 16.144 & $\star * *$ & 0.509 & 0.26 \\
\hline
\end{tabular}

$B=$ unstandardized estimates, $S . E=$ Stander Error, $C . R=$ Critical Ratio, $P=$ probability,$\star \star \star ~=$ significance at 0.001 , sing $=$ significance

\subsection{Objective 3: Groups without PTSD and with PTSD on psychological outcomes as items MIMIC of DIF}

To analyze the equality and differences between participants with and without PTSD groups on the score of each item of the three-factor model of the psychological outcomes, several paths via arrows were linked from the membership group to each item with exception to fixed items from latent variable to that items (e.g., dep1, Anx1, and Ins1) based on procedures of DIF, particularly M-PA method (Fig. 8/9). These procedures were performed within the framework of MIMIC model. Goodness of fit indices in MIMIC model obtained plausible rate $(\mathrm{CFI}(\geq 0.90)=0.932$, IFI $(\geq 0.90)=0.932$, TLI $(\geq 0.90)=0.916$, SRMR $(\leq$ $0.08)=0.044, \operatorname{RMSEA}(\leq 0.08)=0.066, \mathrm{Cl} / \mathrm{HI}(<0.08)=0.062$, and $\mathrm{Cl} / \mathrm{LO}(<0.08)=0.070)(\mathrm{Fig} .8 / 9$ and Table 3). Regarding the Structural Component of MIMIC of DIF, participants without PTSD obtained negatively lower scores (Fig. 8 and Table 8). In contrast, participants with PTSD group in terms of latent traits of depression, anxiety, and insomnia had higher scores with positive direction (Fig. 9 and Table 8). 
Table 8

Parameters of Structural Component of MIMIC for DIF

\begin{tabular}{|c|c|c|c|c|c|c|}
\hline & Group & B & S.E & C.R & $p$ & $\lambda$ \\
\hline \multirow[t]{2}{*}{ Depression } & No PTSD & -0.622 & 0.063 & -9.855 & 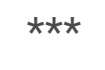 & -0.473 \\
\hline & PTSD & 0.622 & 0.063 & 9.855 & 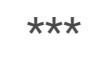 & 0.473 \\
\hline \multirow[t]{2}{*}{ Anxiety } & No PTSD & -0.722 & 0.061 & -11.791 & 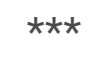 & -0.495 \\
\hline & PTSD & 0.722 & 0.061 & 11.791 & $\star \star \star \star ~$ & 0.495 \\
\hline \multirow[t]{2}{*}{ Insomnia } & No PTSD & -0.964 & 0.070 & -13.853 & 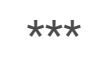 & -0.537 \\
\hline & PTSD & 0.964 & 0.070 & 13.853 & $\star \star \star *$ & 0.537 \\
\hline \multicolumn{7}{|c|}{$\begin{array}{l}\mathrm{B}=\text { unstandardized estimates, } \mathrm{S} . \mathrm{E}=\text { Stander Error, } \mathrm{C} . \mathrm{R}=\text { Critical Ratio, } \mathrm{P}=\text { probability, } \lambda=\text { loading, } \\
\text { significance at } 0.001\end{array}$} \\
\hline
\end{tabular}

Furthermore, one of the substantial benefits of DIF is to check the equivalence of items and functions with two groups, raising specific questions. Thus, what items of psychological outcomes are working equivalently with participants without and with PTSD? Do participants in both groups perceive items of psychological outcomes equivalently?

H1: Items of depression, anxiety, and insomnia match and work equivalently with participants with and without PTSD. The results demonstrated that the hypothesized model of MIMIC for DIF was not statistically significant for certain items (dep2, 3, 4, 5, 6, anx2, 3, 4, 5, 6, 7, ins2, 3, 4, 7) as $T$-value < 1.946 and $p$-value $>0.05$ (Fig. 8/9 and Appendix C). The results confirmed the research hypothesis, and there was no DIF for the mentioned items. Therefore, we can conclude that participants without and with PTSD groups performed equivalently on the above items.

The results indicated that the hypothesized model of MIMIC for DIF was statistically significant for specific items (dep7 and 8, Ins5 and 6) as T-value > 1.946 and $p$-value $<0.05$ (Fig. 8/9 and Appendix C). The items exhibited differential items functioning (DIF) based on the results. That means these items are working differently with participants with and without PTSD. Participants in both groups performed differently on the above items (dep7, 8, ans5, 6). Consistently, two items (dep7 and 8) were working with participants with PTSD higher than participants without PTSD. These items were difficult for participants with PTSD and easy for participants without PTSD. In contrast, two items (Ins 5 and 6) worked with participants with PTSD lower than participants without PTSD. These items were easy for participants with PTSD and difficult for participants without PTSD.

\section{Discussion}


Several pieces of evidence showed that the COVID-19 pandemic has significant psychological repercussions. Recent studies reported that the COVID-19 pandemic is linked to distress, anxiety, depression, and insomnia in the overall population worldwide. In addition, the mental health sequelae of the pandemic are likely to last for months or even years and might peak later than the time of the actual pandemic outbreak. Thus, there is a necessity for further research into how the mental health effects of the COVID-19 pandemic can be mitigated during and after the outbreak [16, 36, 40,52-56]. Therefore, this study aimed to investigate the psychological impact of the COVID-19 pandemic on the overall population in multi-countries during its initial phase.

Our socio-demographic data indicated that participants without PTSD rated higher $(n=639 ; 64 \%)$ than participants with PTSD $(n=360 ; 36.0 \%)$, which means that the PSTD symptoms of the COVID-19 pandemic were lower than recently reported by Pazmino Erazo et al. which exhibited a higher rate of PSTD symptoms (43.8\%) [57]. In addition, the 22-item IES-R scoring diagnosis of PTSD found that males rated $(36.6 \%)$ higher than females (35.6\%). Contrary to our findings, Wang et al. reported that the pandemic's psychological impact on females was more significant than males [24]. Accordingly, the results revealed that group scores of participants without PTSD (Fig. 6) were less and negative on psychological effects such as insomnia, depression, and anxiety than participants with PTSD symptoms who scored high with positive coefficients (Fig. 7). In line with this, groups with and without PTSD on psychological outcomes as Latent Constructs, findings from the current study indicated that participants with PTSD have high scores on depression, anxiety, and insomnia than those without PTSD. Moreover, it is noteworthy to mention that the current study results indicated that IES-R for COVID-19 as a single latent construct has a strong effect on psychological outcomes with a large effect size (0.51) [51]. Furthermore, individual factors of IES-R for COVID-19 (intrusion, avoidance, and hyperarousal) are predictors for individual factors of psychological outcomes (depression, anxiety, and insomnia).

Regarding the psychological effect of COVID-19 using the IES-R scale, it was found that $64.0 \%$ of participants had an average psychological score, whereas $36 \%$ had mild to severe scores on the IES-R, which indicated a stressful impact. Surprisingly, $17.3 \%$ of the participants reported a severe psychological impact. Such findings confirmed that the participants without PTSD rated higher (64.0\%) than those with PTSD (36.0\%).

On the other hand, the results revealed that among participants, $365(36.5 \%)$ had moderate to severe depression symptoms (PHQ-9 score $\geq 10$ ), while 326 (32.6\%) had mild depressive symptoms. However, $308(30.8 \%)$ of participants reported that they did not experience any symptoms of depression (PHQ-9 score $\leq 10)$. These outcomes indicated that more than one-third of respondents included in the study suffered from depressive symptoms. In comparison with previous reports, the present study results are comparable to those of prior studies by Janati Idrissi et al. who reported that $35.6 \%$ of participants had symptoms of depression [58]. However, Choi et al. found that only $19 \%$ of respondents had depression (PHQ-9 score $\geq 10$ ), which presents approximately half of the percentage found in the current study [36]. Also, Alkhamees et al. revealed that $16.4 \%$ of participants had severe depressive symptoms, which is slightly less than half of the percentage found in the current study [52]. Contrary to this, Elhadi et al. 
reported a higher rate of depression symptoms during the COVID-19 pandemic. The authors indicated that $46.2 \%$ of participants experienced symptoms of depression [56].

In respect to anxiety, the results of the current study found that 235 of respondents (23.7\%) (GAD-7 score $\geq 10$ ) had moderate to severe symptoms of anxiety, whereas 331 of participants (33.1\%) had mild symptoms of anxiety. However, 431 (43.1\%) of participants did not experience any symptoms of anxiety. These findings indicated that approximately a quarter of respondents in this study suffered from anxiety symptoms during the COVID-19 pandemic, which was associated with PTSD. In comparison with previous reports, $29.5 \%$ of participants experienced symptoms of anxiety [58], $14 \%$ of respondents had anxiety [36], $13.9 \%$ of responses indicated anxiety symptoms [52], and 19\% of respondents suffered from anxiety symptoms [56].

Insomnia was one of the psychological impacts of the COVID-19 pandemic. The results of the current study found that 515 (51.5\%) among participants experienced symptoms of insomnia based on the Insomnia Severity Index (ISI) (total score $\geq 8$ ). In addition, 484 (48.4\%) of participants reported that they did not experience insomnia symptoms during the pandemic. These findings revealed that the prevalence rate of insomnia symptoms was more than half of the total participants who responded to the questionnaire. Likewise, Janati Idrissi et al. [58] reported that $56.0 \%$ of participants suffered from insomnia symptoms, whereas Zhang et al. [59] inferred that the prevalence rate of insomnia among respondents was $36.1 \%$. The highest rate of insomnia prevalence indicated the significant effect of the COVID-19 pandemic on communities' psychological quality and lifestyle during and in the aftermath of a pandemic. Therefore, these results confirmed the correlation between suffering from insomnia, depression, and anxiety.

On the other hand, groups with PTSD and without PTSD on psychological outcomes as items, DIF results indicated psychological outcomes work equivalently with participants with PTSD and without PTSD. Hence, both groups of participants perceived items of psychological outcomes equivalently. These are true for all psychological outcomes (PHQ-9, GAD-7, and ISI), reflecting measurement invariance and validation of three scales simultaneously. The equivalent results between the two groups (with PTSD and without PTSD) indicated that the instruments used for measuring the psychological outcomes were accurate and carefully prepared by professional experts and consistently with the previous studies $d$ as well $[32,60,61]$.

Differential item functioning (DIF) was found for two items from PHQ-9 (item7 and 8) and two items from ISI (item5 and 6). Differentially functional objects might cause measurement bias; thus, they should be removed or modeled as if they were given to various groups separately. Particularly, one apparent technique for eliminating DIF is to amend or remove DIF items from existing scales and test for DIF regularly when new measures are created. Another option for dealing with DIF is to simulate it [50].

According to Stojanov et al., the COVID-19 pandemic can induce various psychological consequences on people, particularly health care professionals, such as stress, anxiety, depression, insomnia [18]. Therefore, relevant stakeholders, including education authorities, need to establish online portals and 
web-based programs to offer information and other instructional activities throughout the epidemic [62, 63]. Moreover, young people are more receptive to smart devices [64], so the health agencies could consider offering electronic or smartphone-based psycho-education and psychiatric therapies (e.g., cognitive behavior therapy, CBT) to lower the risk of viral spread during face-to-face treatment $[15,65]$. Therefore, this study recommends providing precise interventions and psychological support to individuals and communities suffering from the repercussions of psychological impact/ PTSD of the COVID-19 during and after the pandemic's outbreak.

\subsection{Strengths and Limitations}

This research has four significant novelties at least. The IES-R for COVID-19 is an essential tool for screening distress or traumatic event. One of the vital contributions is to the validity and utilization of the IES-R and for COVID-19 impact. Moreover, the result of the current study provides evidence for the validity of psychological outcomes particularly, depression (PHQ-9), anxiety (GAD-7), and insomnia (ISI). The validation of this research instrument is essential in cross-disciplinary disciplines such as mental health, psychology, public health, and medicine.

IES-R for COVID-19 impact has significant effects on psychological outcomes; particularly, depression (HP-9), anxiety (GAD-7), and insomnia (ISI) at the level of latent constructs (IES-R for COVID-19 and psychological outcomes) and individual factors (intrusion, avoidance, and hyperarousal dimensions with depression, anxiety, and insomnia).

The findings show that items related to depression (PHQ-9), anxiety (GAD-7), and insomnia (ISI) differ among groups validating the scales. There were just a few things that needed to be changed, altered, or modeled. The applications of the Structural Equation Model for MIMIC and MIMIC for DIF are described in a simple and easy-to-understand manner, avoiding the complications of these tools.

Although there are strengths for this research, it has various limitations: 1) this study was performed entirely online. Because of the long working hours and social segregation regulations of health care professionals, it could only be studied cross-sectionally and not longitudinally, 2) the data was acquired only through using an online survey, while interviews; either structured or semi-structured, could not be actualized, 3) the study's findings may not be generalizable due to a lack of a robust sampling frame [66]. However, the researchers opted to conduct the research believing that it is critical to document the secondary traumatization experienced by health care providers and the general public during the COVID process.

Next, healthcare professionals' mental health problems may worsen or improve over time depending on the pandemic's trajectory. As a result, more research into the long-term psychological repercussions of this group is recommended. Several demographic variables, levels of psychological outcomes (e.g., normal, low, moderate, and high), and multi-countries variables are not covered in this research as too many other variables. For example, the level of gender can be assessed to test DIF. 
From a practical perspective, uniform DIF and nonuniform DIF are probably the easiest to conceptualize within MIMIC framework; however, these issues are not widely discussed in the current study, so it is considered one of the limitations.

\section{Conclusion}

This study aims to test the effect of IES-R for COVID-19 on psychological outcomes measured by depression (PHQ-9), anxiety (GAD-7), and insomnia (ISI), and examine the differences between Groups with PTSD and without PTSD on psychological outcomes as latent constructs and items. Results provided evidence that IES-R for COVID-19 strongly affects psychological outcomes (depression, anxiety, and insomnia) with a large effect size using 999 participants from different countries. Participants with PTSD scored high on depression, anxiety, and insomnia than participants without PTSD, who scored lesser. depression (PHQ-9), anxiety (GAD-7), and insomnia (ISI) were validated, resulting as invariant scales among two groups: with and without PTSD, and suggested removing only four items. The results of this study might be used to carry out psychological interventions toward general public people and pay attention to health policymakers to apply effective public mental health strategies to reduce PTSD during the initial stages of the outbreak of the pandemics. Future research is recommended to conduct experimental research on hospital samplings with COVID-19 patients or survivors.

\section{Abbreviations}

Coronavirus disease 2019 (COVID-19); post-traumatic stress disorder (PTSD); Impact of Event ScaleRevised (IES-R); by Patient Health Questionnaire-9 (PHQ-9); Generalized Anxiety Disorder (GAD-7); Insomnia Severity Index (ISI); Confirmatory Factor Analysis (CFA); Structural Equation Modeling (SEM); Multiple Indicators and Multiple Causes (MIMIC); Differential Item Functioning (DIF); Severe Acute Respiratory Syndrome (SARS); Middle East Respiratory Syndrome (MERS); Depression, Anxiety and Stress Scale - 21(DASS-21); Multiple Causes and Multiple Indicators (MCMI); Comparative Fit Index (CFI); Incremental Fit Index (IFI); Tucker Lewis Index (TLI); Standardized Root Mean Residual (SRMR); the Root Mean Squared Error of Approximation (RMSEA); critical ratio (C.R).

\section{Declarations}

\section{- Ethics approval and consent to participate:}

The study was approved by Taiz university research ethics committee with ethic approval reference number: Taiz/RSCGS/2020/03/26/0236. All participants signed an electronic informed consent that included information on the purpose of the study, the methods, the advantages of participation, the voluntary involvement, and the researchers' contact information. We confirm that all methods related to the human participants were performed in accordance with the Declaration of Helsinki.

\section{- Consent for publication:}


Not applicable.

\section{- Availability of data and materials:}

The datasets that support the findings of this study are not openly available. It will be made available from the corresponding author upon reasonable request for academic and research use.

\section{- Competing interests:}

The authors declare that they have no competing interests

\section{- Funding:}

None.

\section{- Authors' Contributions:}

Conceptualization, M.A.A. and R.A.H.; methodology, M.A.A., R.A.H., A.A , M.U.H., and N.A.A.; software, N.A.A.; validation, M.A.A., R.A.H., N.A.A and M.A.Q.; formal analysis, N.A.A., and M.A.A. ; investigation, A.A., M.A.A., M.U.H, and R.A.H.; resources, M.A.A., MA.Q., L.A.M., and S.N.; data curation, M.A.A., M.A.Q., M.U.H., and S.N.; writing-original draft preparation, M.A.A., R.A.H., A.A., M.A.Q., S.N., L.A.M., M.U.H., and N.A.A.; writing-review and editing, M.A.A., R.A.H., A.A., M.A.Q., S.N., L.A.M., M.U.H., and N.A.A.; visualization, M.A.A., MA.Q. and S.N.; supervision, R.A.H.; project administration, M.A.A. and R.A.H.

\section{- Acknowledgements:}

Not applicable.

\section{References}

1. Wang C, Horby PW, Hayden FG, Gao GF: A novel coronavirus outbreak of global health concern. Lancet (London, England) 2020, 395(10223):470-473. doi: 10.1016/S0140-6736(20)30185-9.

2. WHO: Weekly epidemiological update on COVID-19-6 July 2021. World Health Organization https://wwwwhoint/publications/m/item/weekly-epidemiological-update-on-covid-19--6-july-2021 2021.

3. Rothan HA, Byrareddy SN: The epidemiology and pathogenesis of coronavirus disease (COVID-19) outbreak. J Autoimmun 2020, 109:102433. doi: 10.1016/j.jaut.2020.102433.

4. Hamadani JD, Hasan MI, Baldi AJ, Hossain SJ, Shiraji S, Bhuiyan MSA, Mehrin SF, Fisher J, Tofail F, Tipu SMU: Immediate impact of stay-at-home orders to control COVID-19 transmission on socioeconomic conditions, food insecurity, mental health, and intimate partner violence in Bangladeshi women and their families: an interrupted time series. The Lancet Global Health 2020. 
5. Gautam R, Sharma M: 2019-nCoV pandemic: A disruptive and stressful atmosphere for Indian academic fraternity. Brain Behav Immun 2020, 88:948-949. doi: 10.1016/j.bbi.2020.04.025.

6. Hao F, Tan W, Jiang L, Zhang L, Zhao X, Zou Y, Hu Y, Luo X, Jiang X, Mclntyre RS: Do psychiatric patients experience more psychiatric symptoms during COVID-19 pandemic and lockdown? A casecontrol study with service and research implications for immunopsychiatry. Brain, behavior, and immunity 2020. doi: 10.1016/j.bbi.2020.04.069.

7. Aljaberi MA, Alareqe NA, Qasem MA, Alsalahi A, Noman S, Al-Tammemi Aa, Mohamed Ibrahim Ml: Rasch Modeling and Multilevel Confirmatory Factor Analysis for the Usability of the Impact of Event Scale-Revised (IES-R) During the COVID-19 Pandemic. SSRN Electronic Journal 2021. doi: 10.2139/ssrn.3815681.

8. Ala'a B, Barakat M, Doa'a B, Alhallaq SA, Al Hasan DM, Khasawneh GM, Naqera KA, Jaradat RM, Farah FW, Al-Maqableh HO: Beliefs Toward Smoking and COVID-19, and The Pandemic Impact on Smoking Behavior and Quit Intention: Findings from a Community-Based Cross-Sectional Study in Jordan. Available at Research Square 2021. doi: 10.21203/rs.3.rs-580917/v1.

9. Fares ZEA, Al-Tammemi AaB, F. Gadelrab H, Lin C-Y, Aljaberi MA, Alhuwailah A, Roubi ML: Arabic COVID-19 Psychological Distress Scale: development and initial validation. BMJ Open 2021, 11(6):e046006. doi: 10.1136/bmjopen-2020-046006.

10. Zhang Y, Ma ZF: Impact of the COVID-19 pandemic on mental health and quality of life among local residents in Liaoning Province, China: A cross-sectional study. International journal of environmental research public Health Reports 2020, 17(7):2381. doi: 10.3390/ijerph17072381.

11. Lau JT, Yang X, Pang E, Tsui HY, Wong E, Wing YK: SARS-related perceptions in Hong Kong. Emerg Infect Dis 2005, 11(3):417-424. doi: 10.3201/eid1103.040675.

12. Brooks SK, Webster RK, Smith LE, Woodland L, Wessely S, Greenberg N, Rubin GJ: The psychological impact of quarantine and how to reduce it: rapid review of the evidence. The Lancet 2020, 395(10227):912-920. doi: 10.1016/s0140-6736(20)30460-8.

13. Lima CKT, Carvalho PMM, Lima I, Nunes J, Saraiva JS, de Souza RI, da Silva CGL, Neto MLR: The emotional impact of Coronavirus 2019-nCoV (new Coronavirus disease). Psychiatry Res 2020, 287:112915. doi: 10.1016/j.psychres.2020.112915.

14. Sirait LI, Rosyad YS, Meliyana E, Ulfah DM, Pramana C: Stress and Anxiety in the Maternal During the COVID-19 PandemiC. International Journal of Contemporary Medicine 2021, 9(2):7-13.

15. Wang C, Pan R, Wan X, Tan Y, Xu L, Ho CS, Ho RC: Immediate Psychological Responses and Associated Factors during the Initial Stage of the 2019 Coronavirus Disease (COVID-19) Epidemic among the General Population in China. International journal of environmental research and public health 2020, 17(5):1729. doi: 10.3390/ijerph17051729.

16. Dominguez-Salas S, Gómez-Salgado J, Andres-Villas M, Díaz-Milanes D, Romero-Martin M, RuizFrutos C: Psycho-Emotional approach to the psychological distress related to the COVID-19 pandemic in Spain: A Cross-Sectional Observational Study. In: Healthcare: 2020: Multidisciplinary Digital Publishing Institute; 2020: 190. 
17. Arpacioglu S, Gurler M, Cakiroglu S: Secondary Traumatization Outcomes and Associated Factors Among the Health Care Workers Exposed to the COVID-19. Int J Soc Psychiatry 2021, 67(1):84-89. doi: $10.1177 / 0020764020940742$.

18. Stojanov J, Malobabic M, Stanojevic G, Stevic M, Milosevic V, Stojanov A: Quality of sleep and health-related quality of life among health care professionals treating patients with coronavirus disease-19. Int J Soc Psychiatry 2021, 67(2):175-181. doi: 10.1177/0020764020942800.

19. Huang $Y$, Zhao N: Generalized anxiety disorder, depressive symptoms and sleep quality during COVID-19 outbreak in China: a web-based cross-sectional survey. Psychiatry Res 2020, 288:112954. doi: 10.1016/j.psychres.2020.112954.

20. Rias YA, Rosyad YS, Chipojola R, Wiratama BS, Safitri Cl, Weng SF, Yang CY, Tsai HT: Effects of Spirituality, Knowledge, Attitudes, and Practices toward Anxiety Regarding COVID-19 among the General Population in INDONESIA: A Cross-Sectional Study. J Clin Med 2020, 9(12):3798.

21. Civantos AM, Byrnes $Y$, Chang C, Prasad A, Chorath K, Poonia SK, Jenks CM, Bur AM, Thakkar P, Graboyes EM: Mental health among otolaryngology resident and attending physicians during the COVID-19 pandemic: National study. Head \& Neck 2020.

22. Colizzi M, Sironi E, Antonini F, Ciceri ML, Bovo C, Zoccante L: Psychosocial and Behavioral Impact of COVID-19 in Autism Spectrum Disorder: An Online Parent Survey. Brain Sci 2020, 10(6):341. doi: 10.3390/brainsci10060341.

23. Yao H, Chen JH, Xu YF: Patients with mental health disorders in the COVID-19 epidemic. Lancet Psychiatry 2020, 7(4):e21. doi: 10.1016/S2215-0366(20)30090-0.

24. Wang C, Pan R, Wan X, Tan Y, Xu L, Mclntyre RS, Choo FN, Tran B, Ho R, Sharma VK et al: A longitudinal study on the mental health of general population during the COVID-19 epidemic in China. Brain Behav Immun 2020, 87:40-48. doi: 10.1016/j.bbi.2020.04.028.

25. Ho CS, Chee CY, Ho RC: Mental Health Strategies to Combat the Psychological Impact of Coronavirus Disease 2019 (COVID-19) Beyond Paranoia and Panic. Ann Acad Med Singap 2020, 49(3):155-160.

26. Li Z, Ge J, Yang M, Feng J, Qiao M, Jiang R, Bi J, Zhan G, Xu X, Wang $L$ et al: Vicarious traumatization in the general public, members, and non-members of medical teams aiding in COVID19 control. Brain Behav Immun 2020, 88:916-919. doi: 10.1016/j.bbi.2020.03.007.

27. Qiu J, Shen B, Zhao M, Wang Z, Xie B, Xu Y: A nationwide survey of psychological distress among Chinese people in the COVID-19 epidemic: implications and policy recommendations. Gen Psychiatr 2020, 33(2):e100213. doi: 10.1136/gpsych-2020-100213.

28. Qiu JY, Zhou DS, Liu J, Yuan TF: Mental wellness system for COVID-19. Brain Behav Immun 2020, 87:51-52. doi: 10.1016/j.bbi.2020.04.032.

29. Hawton K, Arensman E, Gunnell D, O'Connor R, Appleby L, Khan M, Kapur N, John A, Pirkis J, Collaboration C-SPR: Suicide risk and prevention during the COVID-19 pandemic. Lancet Psychiatry 2020.

30. Zhang MW, Ho CS, Fang P, Lu Y, Ho RC: Methodology of developing a smartphone application for crisis research and its clinical application. Technol Health Care 2014, 22(4):547-559. doi: 
10.3233/THC-140819.

31. Creamer M, Bell R, Failla S: Psychometric properties of the impact of event scale-revised. Behaviour research and therapy 2003, 41(12):1489-1496.

32. Kroenke K, Spitzer RL, Williams JB: The PHQ-9: validity of a brief depression severity measure. J Gen Intern Med 2001, 16(9):606-613. doi: 10.1046/j.1525-1497.2001.016009606.x.

33. Yu X, Tam WW, Wong PT, Lam TH, Stewart SM: The Patient Health Questionnaire-9 for measuring depressive symptoms among the general population in Hong Kong. Comprehensive psychiatry 2012, 53(1):95-102. doi: 10.1016/j.comppsych.2010.11.002.

34. Chin WY, Chan KT, Lam CL, Wong SY, Fong DY, Lo YY, Lam TP, Chiu BC: Detection and management of depression in adult primary care patients in Hong Kong: a cross-sectional survey conducted by a primary care practice-based research network. BMC family practice 2014, 15:30. doi: 10.1186/14712296-15-30.

35. Manea L, Gilbody S, McMillan D: Optimal cut-off score for diagnosing depression with the Patient Health Questionnaire (PHQ-9): a meta-analysis. CMAJ: Canadian Medical Association journal = journal de l'Association medicale canadienne 2012, 184(3):E191-196. doi: 10.1503/cmaj.110829.

36. Choi EPH, Hui BPH, Wan EYF: Depression and Anxiety in Hong Kong during COVID-19. International journal of environmental research and public health 2020, 17(10). doi: 10.3390/ijerph17103740.

37. Lapčević M, Vuković M, Gvozdenović BS, Mioljević V, Marjanović S: Socioeconomic and therapy factor influence on self-reported fatigue, anxiety and depression in rheumatoid arthritis patients. Revista brasileira de reumatologia 2017, 57(6):545-556.

38. Bastien C: Validation of the Insomnia Severity Index as an outcome measure for insomnia research. Sleep Medicine 2001, 2(4):297-307. doi: 10.1016/s1389-9457(00)00065-4.

39. Tan W, Hao F, Mclntyre RS, Jiang L, Jiang X, Zhang L, Zhao X, Zou Y, Hu Y, Luo X: Is returning to work during the COVID-19 pandemic stressful? A study on immediate mental health status and psychoneuroimmunity prevention measures of Chinese workforce. Brain, behavior, and immunity 2020, 87:84-92. doi: 10.1016/j.bbi.2020.04.055.

40. Zhang WR, Wang K, Yin L, Zhao WF, Xue Q, Peng M, Min BQ, Tian Q, Leng HX, Du JL et al: Mental Health and Psychosocial Problems of Medical Health Workers during the COVID-19 Epidemic in China. Psychother Psychosom 2020, 89(4):242-250. doi: 10.1159/000507639.

41. Hu L-t, Bentler PM: Fit indices in covariance structure modeling: Sensitivity to underparameterized model misspecification. Psychological methods 1998, 3(4):424-453. doi: 10.1037/1082989X.3.4.424.

42. Byrne BM: Structural Equation Modeling With AMOS, Third Edition (3rd ed.) edn. New York: routledge; 2016.

43. Tabachnick B, Fidell L: Using Multivariate Statistics, 6 edn. Pearson New International Edition; 2007. 44. Kline RB: Principles and practice of structural equation modeling: Guilford publications; 2015. 
45. Joreskog KG, Goldberger AS: Estimation of a model with multiple indicators and multiple causes of a single latent variable. journal of the American Statistical Association 1975, 70(351a):631-639.

46. Hancock GR: Effect size, power, and sample size determination for structured means modeling and MIMIC approaches to between-groups hypothesis testing of means on a single latent construct. Psychometrika 2001, 66(3):373-388.

47. Muthen BO: Latent variable modeling in heterogeneous populations. Psychometrika 1989, 54(4):557-585.

48. Park SE, Ahn S, Zopluoglu C: Differential Item Functioning Effect Size From the Multigroup Confirmatory Factor Analysis for a Meta-Analysis: A Simulation Study. Educational and psychological measurement 2021, 81(1):182-199. doi: 10.1177/0013164420925885.

49. Wang W-C, Shih C-L: MIMIC Methods for Assessing Differential Item Functioning in Polytomous Items. Applied Psychological Measurement 2010, 34(3):166-180. doi: 10.1177/0146621609355279.

50. Woods CM, Oltmanns TF, Turkheimer E: Illustration of MIMIC-Model DIF Testing with the Schedule for Nonadaptive and Adaptive Personality. Journal of psychopathology and behavioral assessment 2009, 31(4):320-330. doi: 10.1007/s10862-008-9118-9.

51. Cohen J: Statistical power analysis for the behavioral sciences, 2ed edn. Hillsdale, N.J.: L. Erlbaum Associates; 1988.

52. Alkhamees AA, Alrashed SA, Alzunaydi AA, Almohimeed AS, Aljohani MS: The psychological impact of COVID-19 pandemic on the general population of Saudi Arabia. Comprehensive psychiatry 2020, 102:152192. doi: 10.1016/j.comppsych.2020.152192.

53. Odriozola-Gonzalez P, Planchuelo-Gómez A, Irurtia MJ, de Luis-Garcia R: Psychological effects of the COVID-19 outbreak and lockdown among students and workers of a Spanish university. Psychiatry Research 2020, 290:113108. doi: 10.1016/j.psychres.2020.113108.

54. Sher L: The impact of the COVID-19 pandemic on suicide rates. QJM: monthly journal of the Association of Physicians 2020, 113(10):707-712. doi: 10.1093/qjmed/hcaa202.

55. Tan BYQ, Chew NWS, Lee GKH, Jing M, Goh Y, Yeo LLL, Zhang K, Chin HK, Ahmad A, Khan FA et al: Psychological Impact of the COVID-19 Pandemic on Health Care Workers in Singapore. Ann Intern Med 2020, 173(4):317-320. doi: 10.7326/M20-1083.

56. Elhadi M, Alsoufi A, Msherghi A, Alshareea E, Ashini A, Nagib T, Abuzid N, Abodabos S, Alrifai H, Gresea E et al: Psychological Health, Sleep Quality, Behavior, and Internet Use Among People During the COVID-19 Pandemic: A Cross-Sectional Study. Frontiers in psychiatry 2021, 12:632496. doi: 10.3389/fpsyt.2021.632496.

57. Pazmino Erazo EE, Alvear Velasquez MJ, Saltos Chavez IG, Pazmino Pullas DE: Factors Associated With Psychiatric Adverse Effects in Healthcare Personnel During the COVID-19 Pandemic in Ecuador. Rev Colomb Psiquiatr (Engl Ed) 2021:S0034-7450(0021)00031-00037. doi: 10.1016/j.rcp.2020.12.007.

58. Janati Idrissi A, Lamkaddem A, Benouajjit A, Ben El Bouaazzaoui M, El Houari F, Alami M, Labyad S, Chahidi A, Benjelloun M, Rabhi S et al: Sleep quality and mental health in the context of COVID-19 
pandemic and lockdown in Morocco. Sleep Med 2020, 74:248-253. doi:

10.1016/j.sleep.2020.07.045.

59. Zhang C, Yang L, Liu S, Ma S, Wang Y, Cai Z, Du H, Li R, Kang L, Su M et al: Survey of Insomnia and Related Social Psychological Factors Among Medical Staff Involved in the 2019 Novel Coronavirus Disease Outbreak. Frontiers in psychiatry 2020, 11:306. doi: 10.3389/fpsyt.2020.00306.

60. Morin $\mathrm{CM}$, Belleville G, Belanger L, Ivers $\mathrm{H}$ : The Insomnia Severity Index: psychometric indicators to detect insomnia cases and evaluate treatment response. Sleep 2011, 34(5):601-608. doi: 10.1093/sleep/34.5.601.

61. Spitzer RL, Kroenke K, Williams JB, Lowe B: A brief measure for assessing generalized anxiety disorder: the GAD-7. Arch Intern Med 2006, 166(10):1092-1097. doi: 10.1001/archinte.166.10.1092.

62. Zhang MW, Ho C, Fang P, Lu Y, Ho RC: Usage of social media and smartphone application in assessment of physical and psychological well-being of individuals in times of a major air pollution crisis. JMIR Mhealth Uhealth 2014, 2(1):e16. doi: 10.2196/mhealth.2827.

63. Zhang MW, Ho CS, Ho RC: Methodology of development and students' perceptions of a psychiatry educational smartphone application. Technol Health Care 2014, 22(6):847-855. doi: 10.3233/THC140861.

64. Do TTT, Le MD, Van Nguyen T, Tran BX, Le HT, Nguyen HD, Nguyen LH, Nguyen CT, Tran TD, Latkin CA et al: Receptiveness and preferences of health-related smartphone applications among Vietnamese youth and young adults. BMC Public Health 2018, 18(1):764. doi: 10.1186/s12889-0185641-0.

65. Wang C, Pan R, Wan X, Tan Y, Xu L, Mclntyre RS, Choo FN, Tran B, Ho R, Sharma VK et al: A longitudinal study on the mental health of general population during the COVID-19 epidemic in China. Brain, behavior, and immunity 2020, 87:40-48. doi: 10.1016/j.bbi.2020.04.028.

66. Pierce M, Hope H, Ford T, Hatch S, Hotopf M, John A, Kontopantelis E, Webb R, Wessely S, McManus $S$ et al: Mental health before and during the COVID-19 pandemic: a longitudinal probability sample survey of the UK population. The Lancet Psychiatry 2020, 7(10):883-892. doi: 10.1016/s22150366(20)30308-4.

\section{Figures}




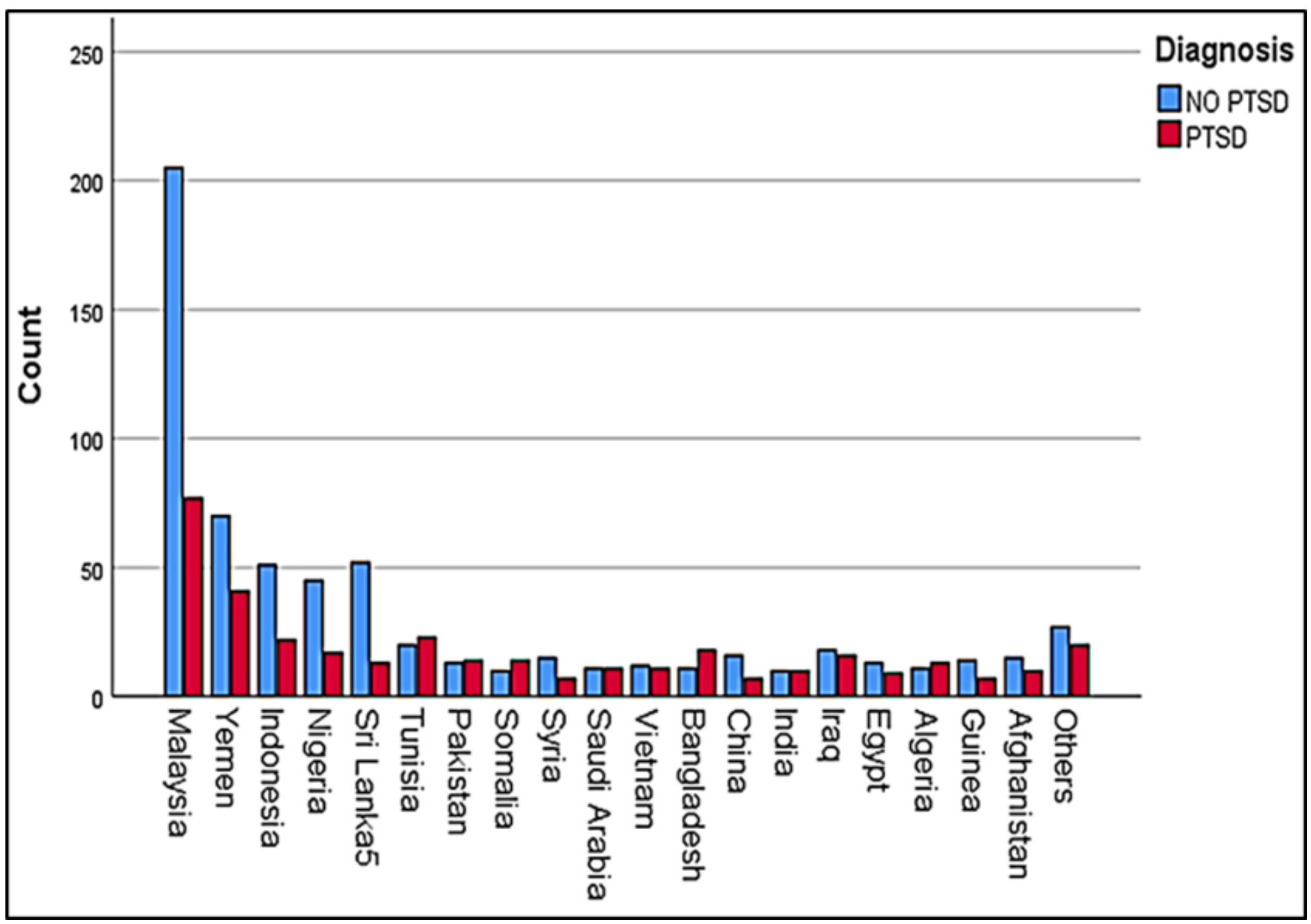

Figure 1

Lists of countries involved in the present study. 


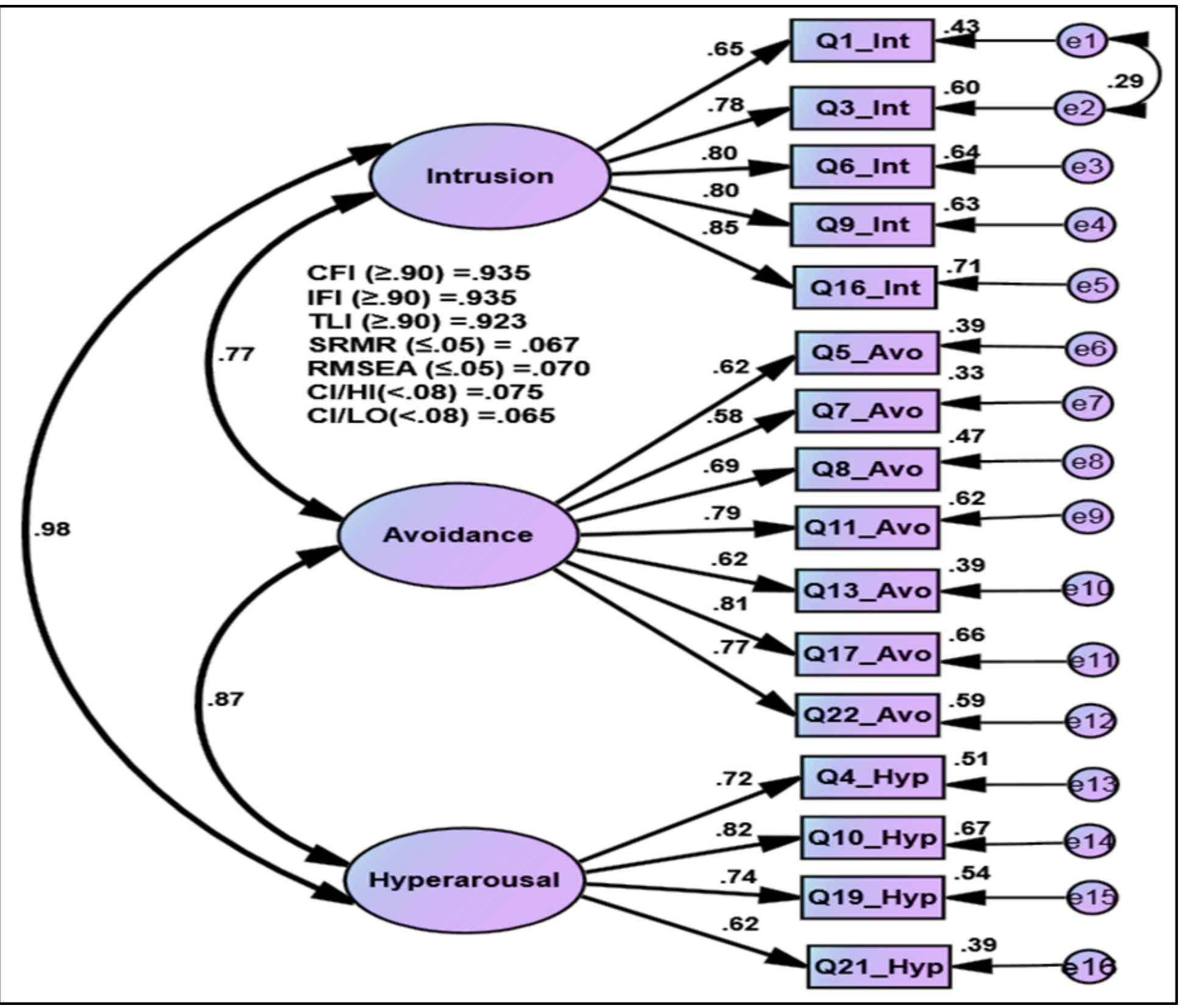

Figure 2

Confirmatory Factor Analysis (CFA) for IES-R for COVID-19 


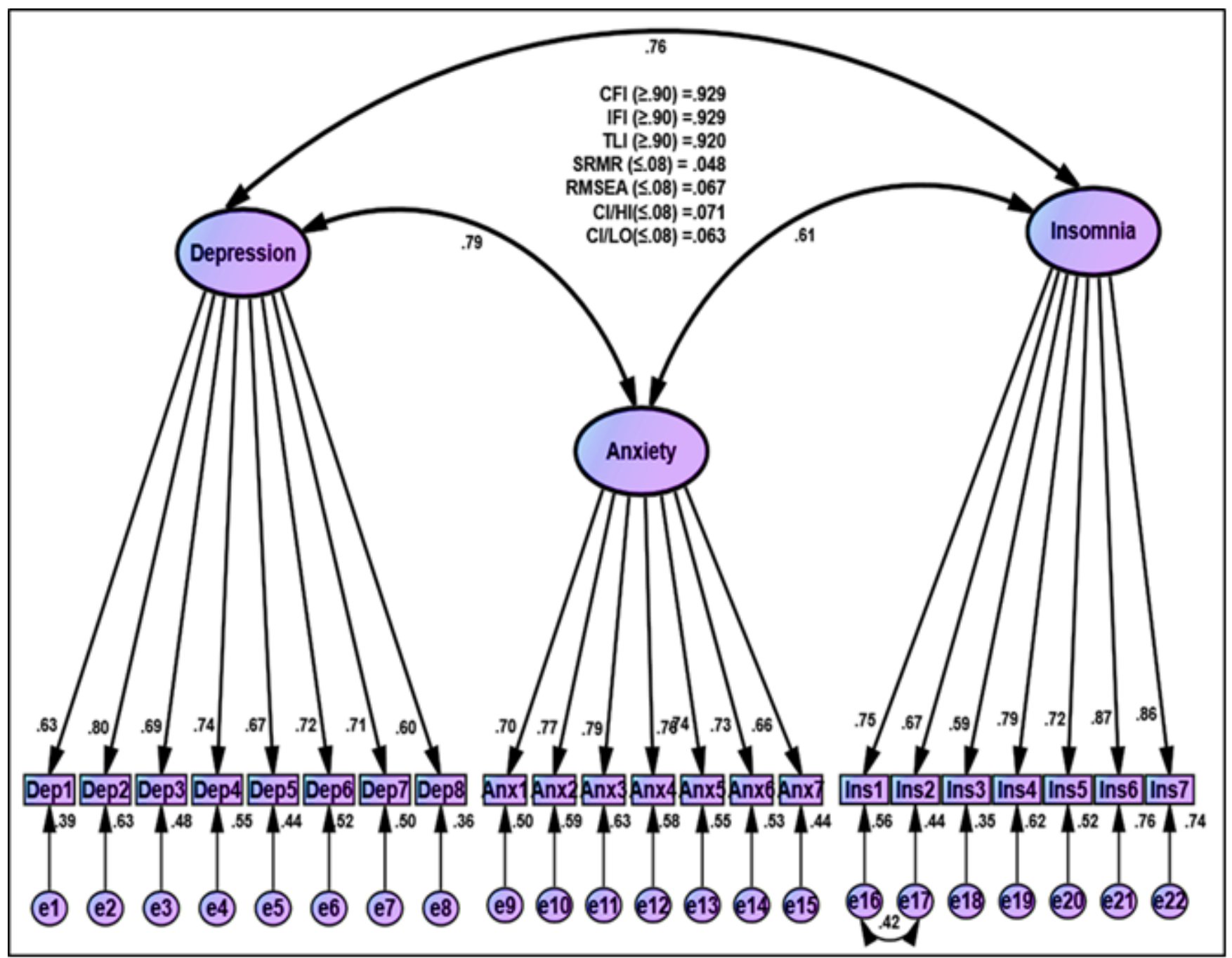

Figure 3

CFA for Psychological Outcomes (Depression, Anxiety, and Insomnia) 


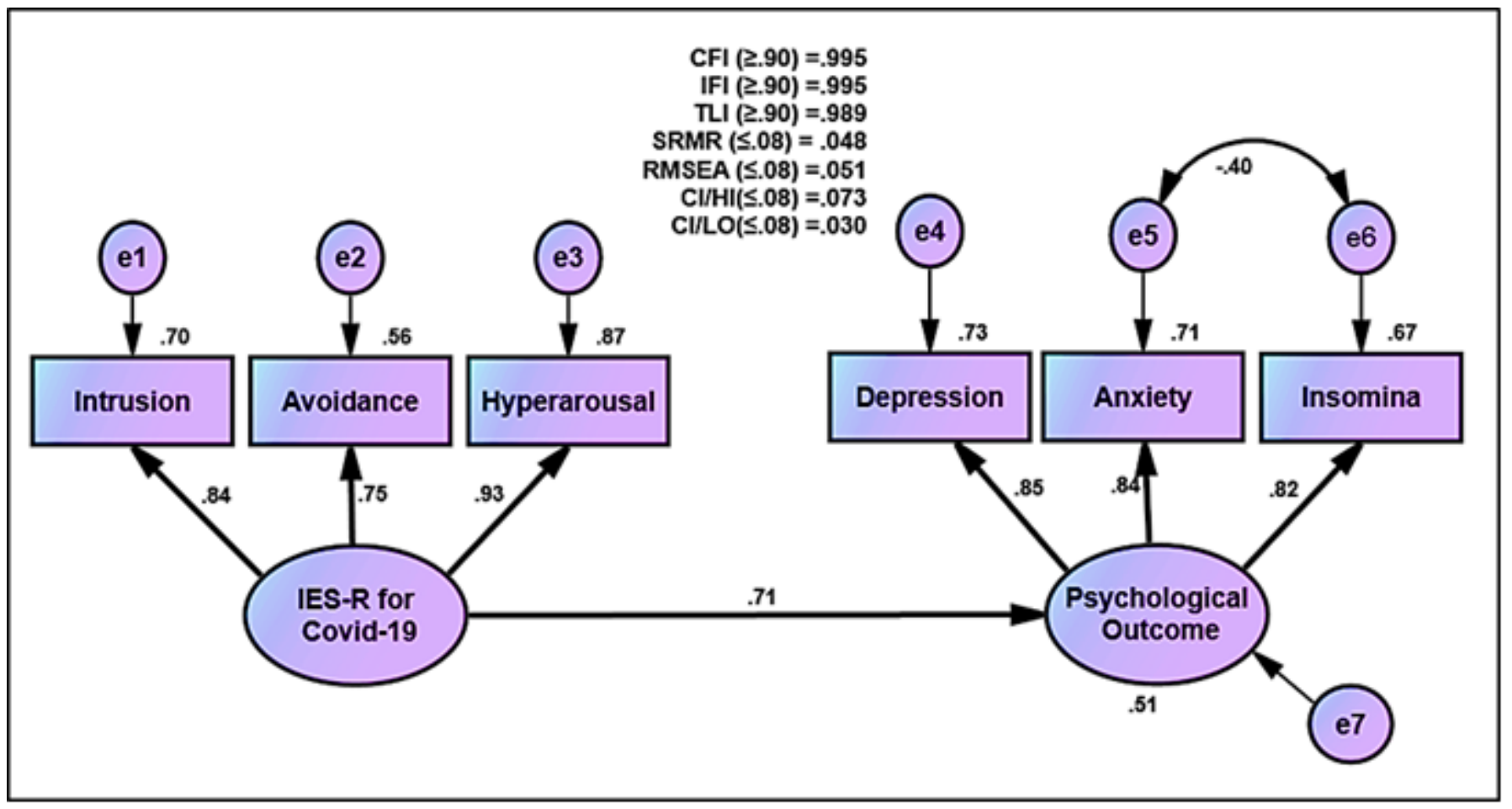

Figure 4

Effect of IES-R for Covid-19 on Psychological Outcomes

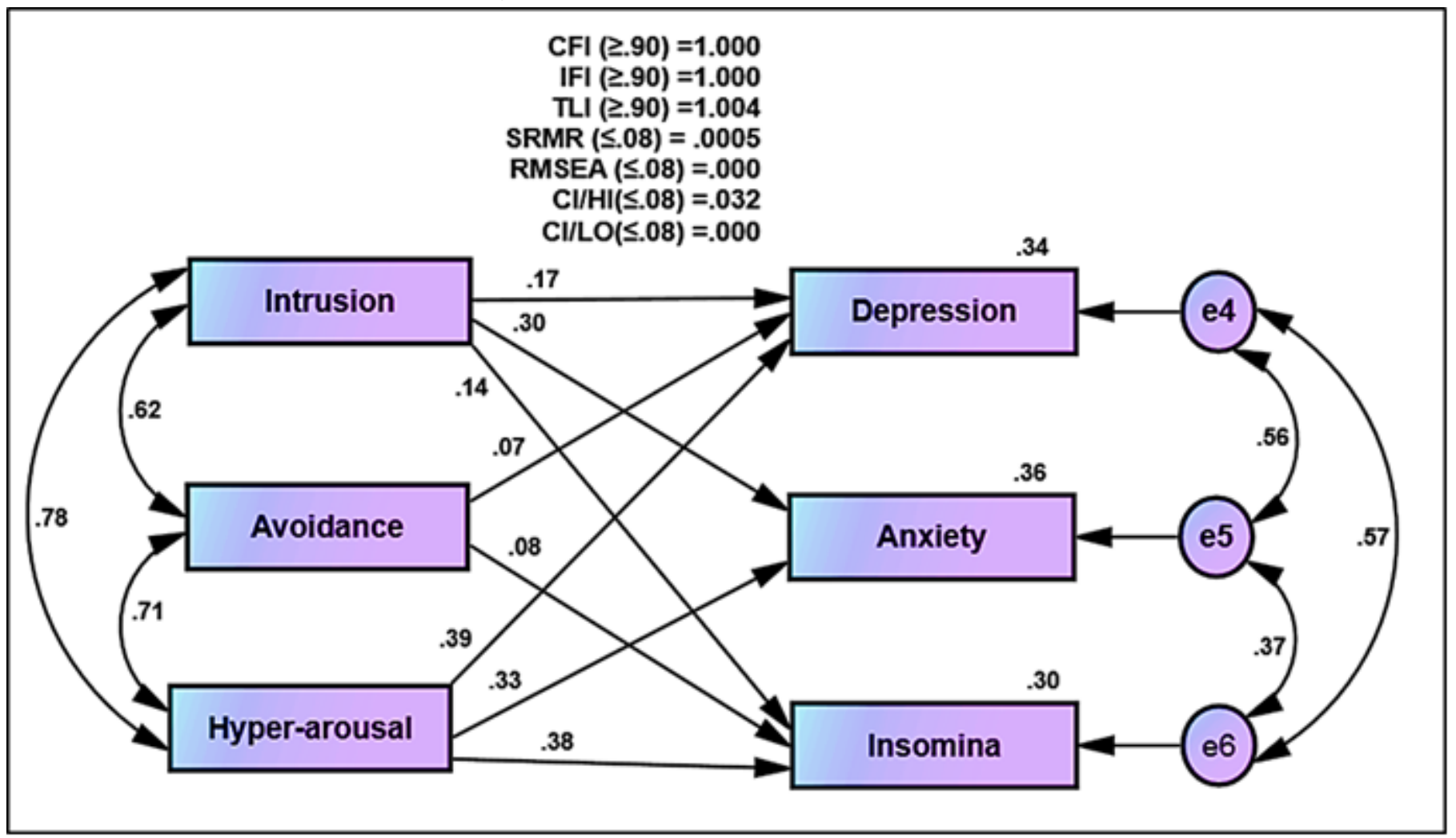

Figure 5

Effect of IES-R for Covid-19 on Psychological Outcomes (individual factors) 


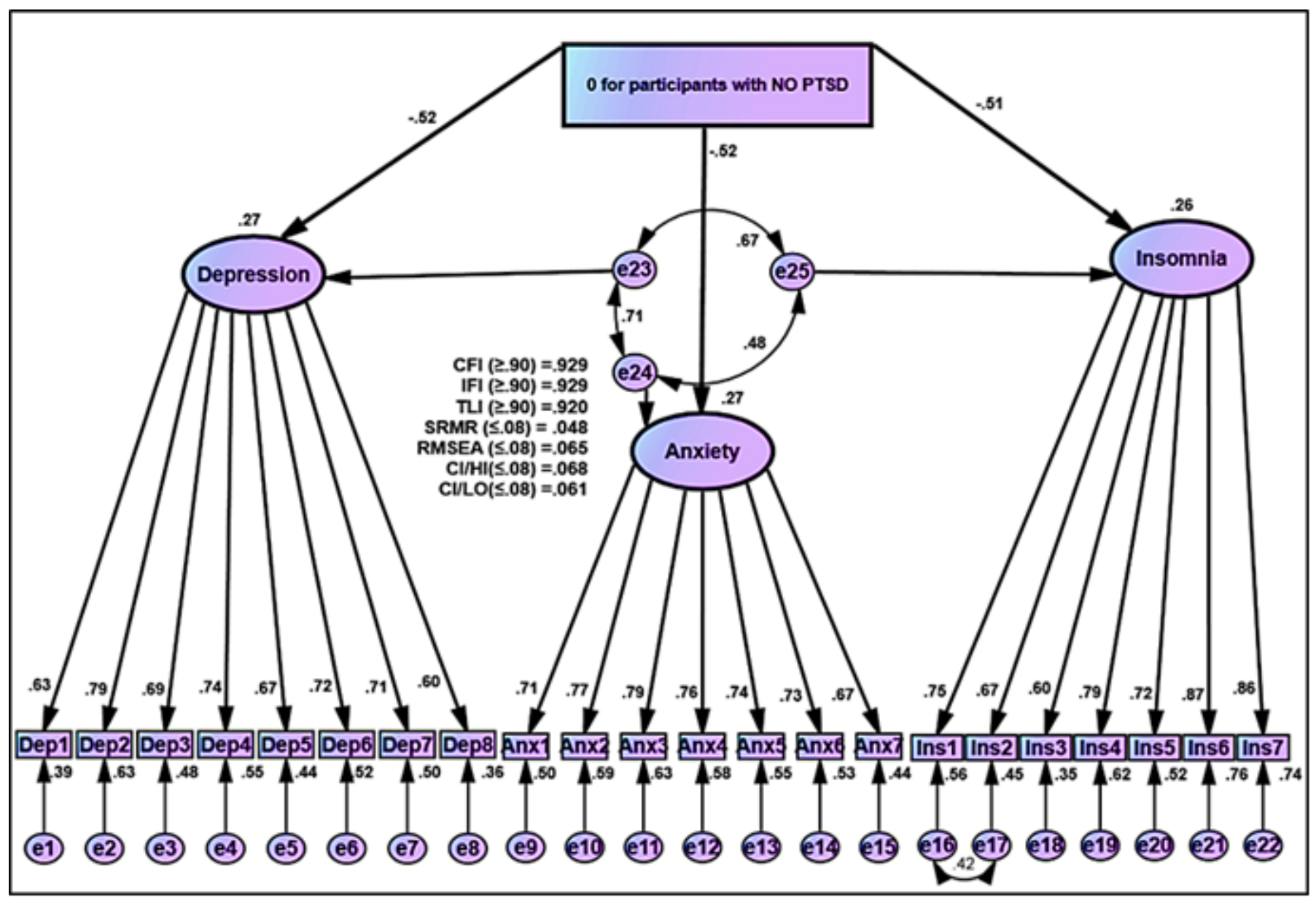

Figure 6

MIMIC Model for Participants without PTSD based on IES-R for Covid-19 on Psychological Outcomes (Depression, Anxiety, and Insomnia) 


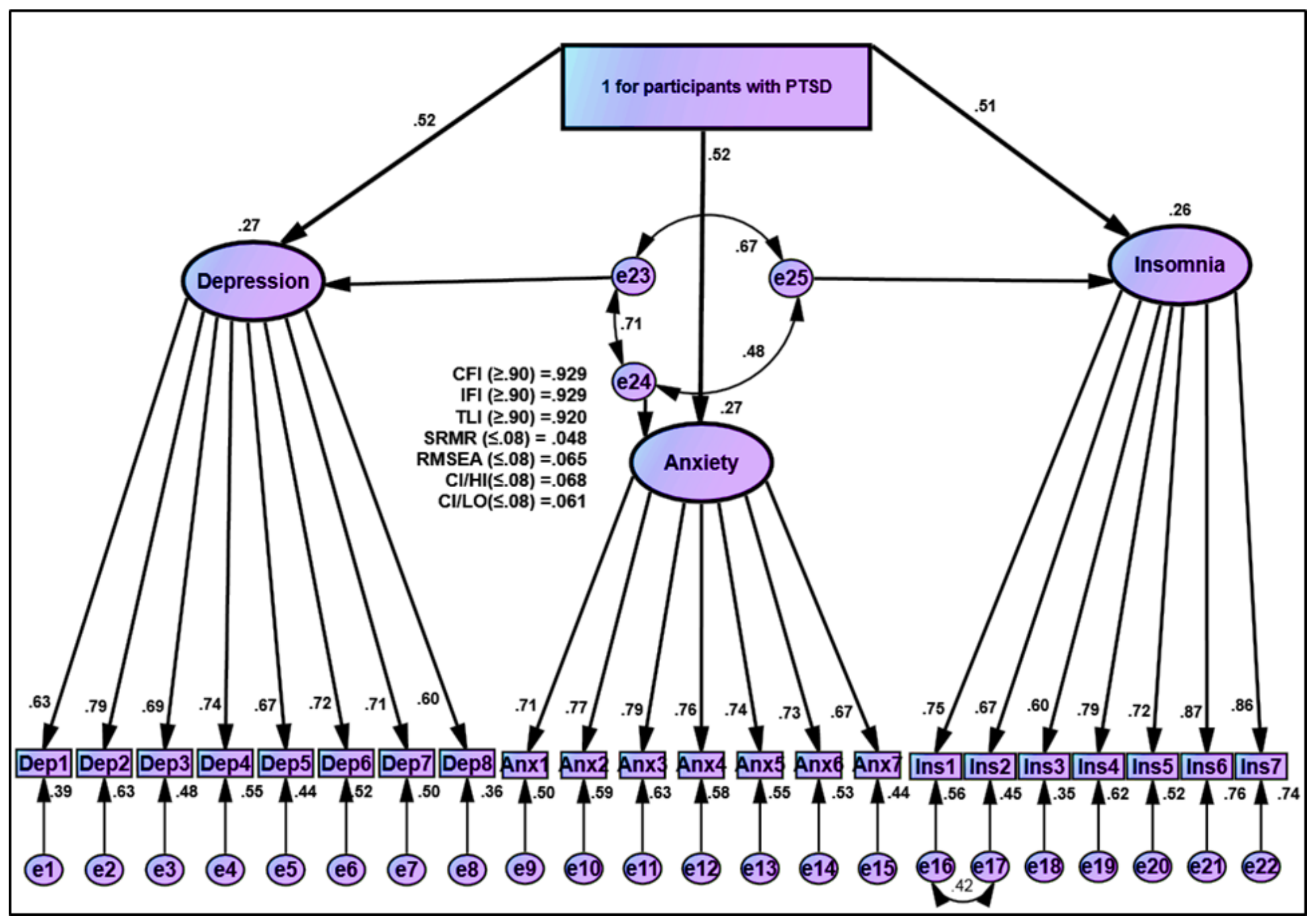

Figure 7

MIMIC Model for Participants with PTSD based on IES-R for Covid-19 on Psychological Outcomes (Depression, Anxiety, and Insomnia). 


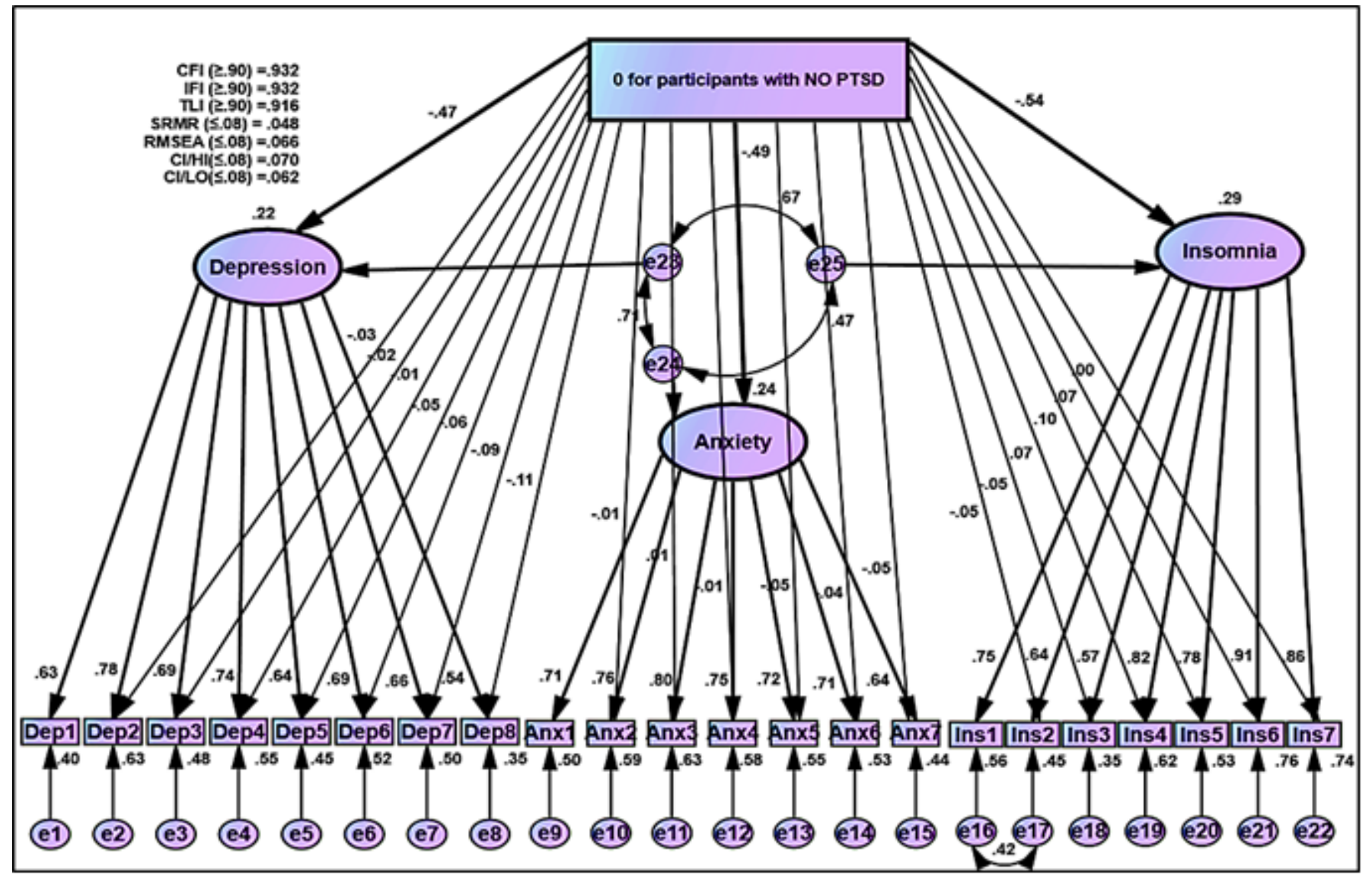

Figure 8

MIMIC for DIF for Participants without PTSD based on IES-R for Covid-19

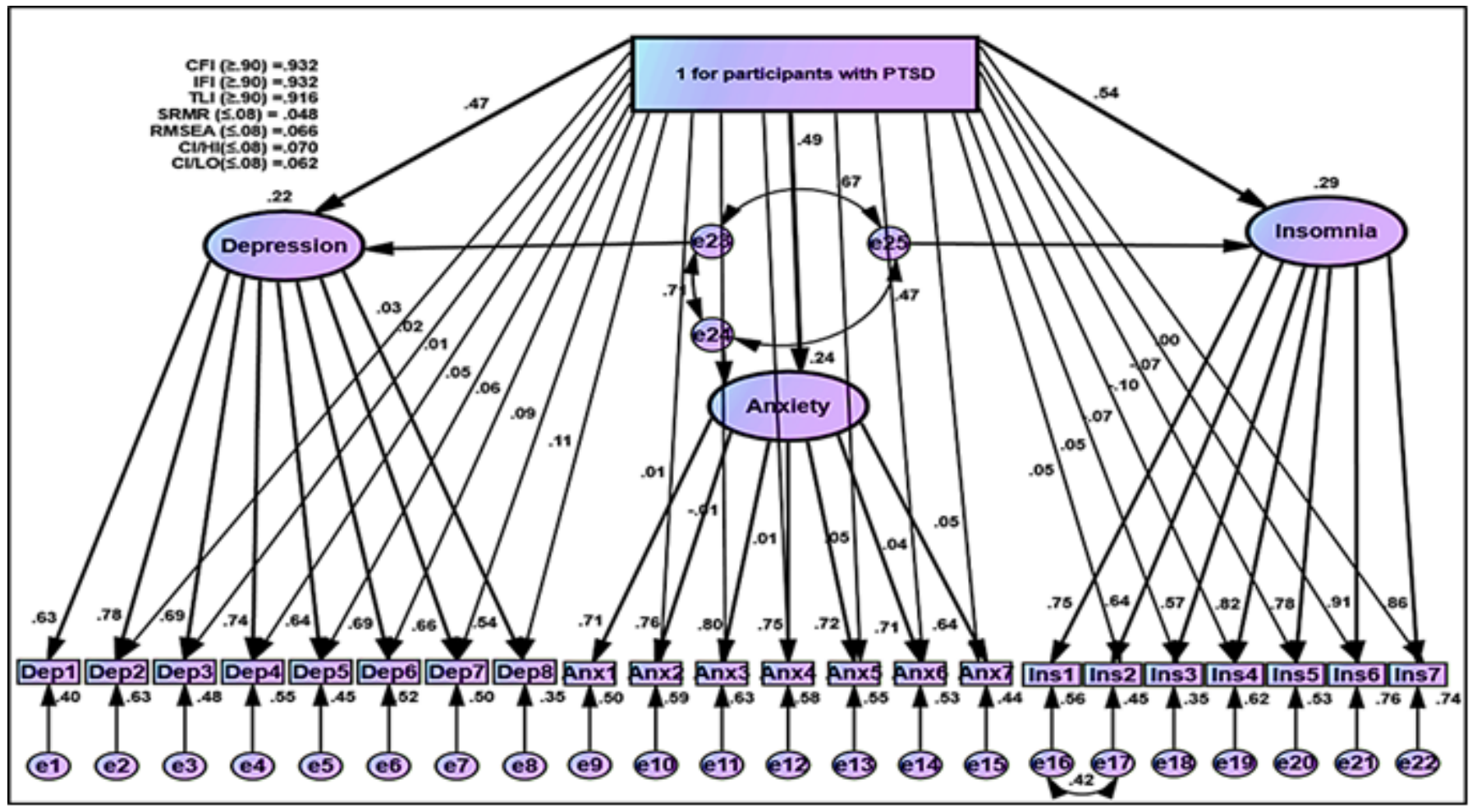

Figure 9 
MIMIC for DIF for Participants with PTSD based on IES-R for Covid-19

\section{Supplementary Files}

This is a list of supplementary files associated with this preprint. Click to download.

- AppendixA.docx 